\title{
A Mixture of Ginkgo biloba L. Leaf and Hericium erinaceus (Bull.) Pers. Fruit Extract Attenuates Scopolamine-Induced Memory Impairments in Mice
}

\author{
Seong Min Hong, ${ }^{1}$ Da Hye Yoon, ${ }^{1}$ Mi Kyeong Lee, ${ }^{2}$ Jae Kang Lee, ${ }^{3}$ and Sun Yeou Kim $\mathbb{D}^{1}$ \\ ${ }^{1}$ College of Pharmacy and Gachon Institute of Pharmaceutical Science, Gachon University, 191, Hambakmoe-ro, Yeonsu-gu, \\ Incheon 21936, Republic of Korea \\ ${ }^{2}$ College of Pharmacy, Chungbuk National University, Cheongju 28160, Republic of Korea \\ ${ }^{3}$ CNGBio Co., Cheongju 28655, Republic of Korea
}

Correspondence should be addressed to Sun Yeou Kim; sunnykim@gachon.ac.kr

Received 9 March 2021; Revised 21 December 2021; Accepted 31 December 2021; Published 27 January 2022

Academic Editor: Tim Hofer

Copyright (c) 2022 Seong Min Hong et al. This is an open access article distributed under the Creative Commons Attribution License, which permits unrestricted use, distribution, and reproduction in any medium, provided the original work is properly cited.

\begin{abstract}
Alzheimer's disease (AD) is a neurodegenerative disease that is characterized by loss of memory and cognitive impairment via dysfunction of the cholinergic nervous system. In cholinergic dysfunction, it is well known that impaired cAMP response element-binding protein (CREB) and brain-derived neurotrophic factor (BDNF) signaling are major pathological markers and are some of the strategies for the development of $\mathrm{AD}$ therapy. Therefore, this study is aimed at evaluating whether a mixture comprising Ginkgo biloba L. leaf (GL) and Hericium erinaceus (Bull.) Pers. (HE) fruit extract (GH mixture) alleviated cognitive impairment induced in a scopolamine-induced model. It was discovered that GH reduced neuronal apoptosis and promoted neuronal survival by activating BDNF signaling in an in vitro assay. In addition, the GH (p.o. $240 \mathrm{mg} / \mathrm{kg}$ ) oral administration group significantly restored the cognitive deficits of the scopolamine-induced mouse group (i.p. $1.2 \mathrm{mg} / \mathrm{kg}$ ) in the behavior tests such as Y-maze and novel object recognition task (NORT) tests. This mixture also considerably enhanced cholinergic system function in the mouse brain. Furthermore, GH markedly upregulated the expressed levels of extracellular signal-regulated kinase (ERK), CREB, and BDNF protein levels. These results demonstrated that GH strongly exerted a neuroprotective effect on the scopolamine-induced mouse model, suggesting that an optimized mixture of GL and HE could be used as a good material for developing functional foods to aid in the prevention of neurodegenerative diseases, including AD.
\end{abstract}

\section{Introduction}

Alzheimer's disease (AD), which involves continuous memory and cognitive dysfunction, is an age-related neurodegenerative disease [1]. As mentioned in the World Health Organization (WHO) report, this disease is one of the rapidly increasing chronic diseases that is globally affecting approximately 30 million people over the age of 60 years each year [2]. Acetylcholine (ACh) released from the hippocampus and cortex plays a vital role in attention, memory, and learning [3]. However, the brain of $\mathrm{AD}$ patients has critically elevated levels of acetylcholinesterase (AChE), which is involved in the breakdown of $\mathrm{ACh}$, resulting in a loss of memory and cognitive functions [4]. It is clear that dysfunction of cholinergic neurons is mainly involved in $\mathrm{AD}$ pathogenesis [5]. Hence, the development of AD therapy has mainly focused on the protective effect on the cholinergic system. Several drugs, as acetylcholinesterase inhibitors (e.g., tacrine, rivatigmine, galantamine, and donepezil), have been approved for the treatment of $\mathrm{AD}$, but they only help in keeping symptoms from worsening [6]. However, they have short half-lives and side effects such as hepatotoxicity and nausea [7]. Thus, it is needed to find alternative drugs to treat $\mathrm{AD}$ which show strong effects without any toxicity.

Many studies have shown that the scopolamine-induced $\mathrm{AD}$ model is useful for evaluating $\mathrm{AD}$ progression $[8,9]$. 
Scopolamine, an ACh antagonist that leads to cholinergic dysfunction, is a tropane alkaloid that has been used for studying cognitive deficits in preclinical studies [10]. Numerous studies have already demonstrated that memory impairment in the scopolamine-induced mouse model is correlated with the production of oxidative stresses, such as through reactive oxygen species (ROS) from the brain via the dysfunction of antioxidant enzymes [11]. Moreover, it has been reported that scopolamine interferes with the neuronal protection mechanisms, including extracellular signal-regulated kinase (ERK) and cAMP response element-binding protein (CREB)/brain-derived neurotrophic factor (BDNF) mouse studies [12-14].

Meanwhile, cognitive enhancers, also known as nootropics, have been studied with respect to alleviating the suffering of $\mathrm{AD}$ patients [15]. Nootropics improve learning and memory through several mechanisms (i.e., blockage of calcium channels, inhibition of AChE activities, enhancement of the levels of antioxidants, and synaptic and mitochondrial responses genes) [16]. Indeed, these agents also show neuroprotective effects via amyloid beta accumulation, synaptic dysfunctions, apoptosis, inflammation, and oxidative stress [15]. Many types of nootropics, which are drugs or herbal agents that improve memory function, have been reported [17]. The two kinds of nootropics are synthetic compounds (e.g., piracetam) and natural/herbal nootropics (e.g., Ginkgo biloba L. leaf (GL) and Hericium erinaceus (Bull.) Pers. (HE)) [17-20]. In particular, natural nootropics act through various mechanisms in the brain [15]: (1) modulating neurotransmitter release, (2) improving neuronal function, (3) protecting against oxidative damage, and (4) serving as an energy booster. In addition, the application of nootropics for chronic treatment shows improvement in memory function via the regulation of ERK/CREB/BDNF pathways on the hippocampus. In view of the aforementioned points, nootropics from natural resources are recognized as alternative materials used to improve the cognitive impairment in AD.

Clinical studies with GL in dementia patients have pointed out that it slows down the decline in mental function and neuropsychiatric symptoms. In addition, GL showed efficacy and safety for treatment of cognitive impairment and dementia in clinical studies [21, 22]. HE revealed that it ameliorated BDNF levels and depressive behavior in chronically stressed animals, improved memory impairment, protected neurons from neurotoxicity (e.g., beta-amyloid, hydrogen peroxide, and lipopolysaccharide), and restored hippocampal damage after pilocarpine-induced status epilepticus [19, 23-25]. The well-known edible nutrient nootropics, such as GL and HE, are cognitive enhancers. Nevertheless, it is reported that each such agent may not have any effect on memory dysfunction. This study was thus carried out to investigate the synergic effects of the improvement in cognitive function, both in vitro and in vivo.

\section{Materials and Methods}

2.1. Materials. Anti-Bax, anti-Bcl-2, anti-cleaved-caspase-3, anti-BDNF, anti-CREB, anti-phosphorylated CREB
(pCREB), anti-ERK, anti-pERK, anti-protein kinase B (AKT), anti-pAKT, anti-glycogen synthase kinase 3 beta (GSK3 $\beta$ ), anti-pGSK3 $\beta$, and glyceraldehyde 3-phosphate dehydrogenase (GAPDH) were purchased from Cell Signaling Technology (Beverly, MA, USA). 3-(4,5-Dimethylthiazol-2-yl)-2,5-diphenyl-tetrazolium bromide (MTT), dimethyl sulfoxide (DMSO), 2', $7^{\prime}$-dichlorofluorescein diacetate (DCFH-DA), scopolamine, and donepezil hydrochloride were obtained from Sigma-Aldrich (St. Louis, MO, USA). The mitochondrial membrane potential assay kit (JC-10) and anti-doublecortin (DCX) were purchased from Abcam (Cambridge, MA, USA).

2.2. Preparation of GL and HE. The G. biloba L. leaf extract (lot number Kgb-191122, GL) containing 24\% flavone, and $<5 \mathrm{ppm}$ ginkgolic acid was provided by SAS KPLC (Paris, France). Hericium erinaceus (Bull.) Pers. fruit was supplied by the CNGBio company (Cheongju, Korea). The dried fruit bodies of $\mathrm{H}$. erinaceus (Bull.) Pers. were extracted two times with $70 \% \mathrm{EtOH}$ for $2 \mathrm{~h}$ at $85^{\circ} \mathrm{C}$ and condensed using a rotary evaporator. Yield value of $H$. erinaceus (Bull.) Pers. (HE) extract was $43.32 \%$. The GL and HE were prepared in DMSO and mixed in a 1:5 ratio $(\mathrm{GH})$ for in vitro and in vivo tests.

2.3. High-Performance Liquid Chromatography (HPLC) Analysis of $\mathrm{GH}$. GH, which was mixed in a ratio 1:5 of GL and HE, was analyzed using a Waters e2695 Separation Module (Waters Corp., Milford, MA, USA) with a 2998 Photodiode Array Detector. For the analysis of kaempferol, quercetin, isorhamnetin, and acacetin from GH, twenty milligrams of GH mixture and standard compounds $(0.1,1$, and $10 \mu \mathrm{g} / \mathrm{mL}$ ) were dissolved in $50 \%$ acetonitrile/water. The mobile phase consisted of $0.4 \%$ phosphoric acid/water (solvent $A$ ) and acetonitrile (solvent $B$ ) with the following gradient: 0-10 min, $10 \% \mathrm{~B} ; 10-40 \mathrm{~min}, 10-70 \% \mathrm{~B} ; 40-44 \mathrm{~min}, 70-$ $100 \% \mathrm{~B}$; and $44-47 \mathrm{~min}, 0 \% \mathrm{~B}$, with a flow rate of $1 \mathrm{~mL} / \mathrm{min}$ [26]. For the analysis of hericene $\mathrm{A}$ and hericene $\mathrm{D}$ from $\mathrm{GH}$, three milligrams of $\mathrm{GH}$ mixture and standard compounds $(0.1,1$, and $10 \mu \mathrm{g} / \mathrm{mL})$ were dissolved in $30 \%$ ethyl acetate/methanol. For isocratic analyses, the mobile phase consisted of $97 \%$ methanol $/ 3 \%$ water with a flow rate of $1 \mathrm{~mL} / \mathrm{min}$ [27]. For the analysis of ginkgolide A and ginkgolide $\mathrm{B}$, twenty milligrams of $\mathrm{GH}$ mixture and standard compounds $(1,10$, and $100 \mu \mathrm{g} / \mathrm{mL}$ ) were dissolved in $50 \%$ methanol/water. For isocratic analyses, the mobile phase consisted of $72.5 \%$ water $/ 17.5 \%$ water $/ 10 \%$ isopropanol with a flow rate of $1 \mathrm{~mL} / \mathrm{min}$ [28]. All analyses used a Kromasil $\mathrm{C}^{18}$ column $(150 \mathrm{~mm} \times 4.6 \mathrm{~mm}, 5 \mu \mathrm{m})$. The column temperature was set at $30^{\circ} \mathrm{C}$, and the PDA detector was set at 280 $340 \mathrm{~nm}$ to acquire chromatograms.

2.4. Cell Culture. Human neuroblastoma SH-SY5Y cells were obtained from the Korea Cell Line Bank (Seoul, Korea) and maintained in Dulbecco's modified Eagle's medium (GIBCO/Invitrogen, Carlsbad, CA, USA) supplemented with $10 \%$ fetal bovine serum (GIBCO, Carlsbad, CA, USA) and $1 \%$ penicillin-streptomycin (GIBCO/Invitrogen, Carlsbad, $\mathrm{CA}, \mathrm{USA})$ at $37^{\circ} \mathrm{C}$ in a humidified atmosphere 
containing $5 \% \mathrm{CO}_{2}$. SH-SY5Y cells were seeded in 96- and 6 -well plates at densities of $4 \times 10^{4}$ cells/well and $1 \times 10^{6}$ cells/well, respectively.

2.5. Cell Viability. Cell viability was measured using a 2.4.3(4,5-dimethylthiazol-2-yl)-2,5-diphenyltetrazolium bromide (MTT) assay according to Venkatesan et al. [29]. SH-SY5Y cells were seeded in 96-well plates and pretreated with various concentrations of GH (dissolved in PBS), hericene A, hericene $\mathrm{D}$, ginkgolide $\mathrm{A}$, ginkgolide $\mathrm{B}$, isorhamnetin, acacetin, quercetin, and kaempferol. All standard components were dissolved in DMSO. After incubation for $1 \mathrm{~h}$ at $37^{\circ} \mathrm{C}$, scopolamine was cotreated with $\mathrm{GH}$ for $24 \mathrm{~h}$ at $37^{\circ} \mathrm{C}$. The reaction medium was removed, and $0.5 \mathrm{mg} / \mathrm{mL}$ of MTT solution was added. The treated cells were incubated at $37^{\circ} \mathrm{C}$ for $1 \mathrm{~h}$. The medium was removed, and $200 \mu \mathrm{L}$ of DMSO was added. This assay was performed at $570 \mathrm{~nm}$ using a microplate reader (Bio-Rad, Hercules, CA, USA). Cell morphology was detected using a 10x objective (scale bar $=50 \mu \mathrm{m})$ in the InCucyte ZOOM Live Cell Analysis System (Essen Instruments, Ann Arbor, MI, USA).

2.6. Measurement of Reactive Oxygen Species (ROS) Production. SH-SY5Y cells were seeded in 96-well plates and pretreated with various concentrations of GH (dissolved in PBS). After incubation for $1 \mathrm{~h}$ at $37^{\circ} \mathrm{C}$, scopolamine was cotreated with GH for $1 \mathrm{~h}$. Afterwards, $30 \mu \mathrm{M}$ DCFH-DA was added to the culture medium for $30 \mathrm{~min}$ at $37^{\circ} \mathrm{C}$. The fluorescence of DCF, which is the oxidation product of DCFH-DA, was measured (excitation $($ Ex)/emission $(E m)=485 / 535 \mathrm{~nm}$ ) using a VICTOR X3 plate reader (Perkin Elmer, Waltham, MA, USA) [30].

\subsection{Measurement of Mitochondrial Membrane Potential.} The mitochondrial membrane potential assay was carried out using a JC-10 kit (Abcam, CA, USA) [31]. SH-SY5Y cells were seeded in 96-well plates and pretreated with various concentrations of GH (dissolved in PBS). After incubation for $1 \mathrm{~h}$ at $37^{\circ} \mathrm{C}$, scopolamine was cotreated with $\mathrm{GH}$ for $24 \mathrm{~h}$ at $37^{\circ} \mathrm{C}$. After treatment, the cell mitochondria were stained using $50 \mu \mathrm{L}$ of JC-10 solution for $30 \mathrm{~min}$ at $37^{\circ} \mathrm{C}$ and kept away from light. After incubation, $50 \mu \mathrm{L}$ of buffer $\mathrm{B}$ solution was added into the JC-10 loading plate before reading the fluorescence intensity, and this was analyzed using a microplate reader (BioTek Instruments Inc., Winooski, VT, USA). The fluorescence intensities were measured at $E x / E m=490 / 525 \mathrm{~nm}$ and $490 / 590 \mathrm{~nm}$ for ratio analysis.

2.8. Animal Study. Institute of Cancer Research (ICR, 6 weeks old, male) mice were obtained from Orient Bio Inc. (Gyeonggi-do, Korea). Each mouse was housed in ventilated cages under a specific pathogen-free environment (temperature, $23 \pm 2^{\circ} \mathrm{C}$; relative humidity, $55 \pm 5 \%$ ). Mice were fed an AIN-76A purified rodent diet (Central Laboratory Animal Inc., Seoul, Korea) and given water ad libitum. All mice $(n=60)$ were randomly divided into six groups $(n=10$ per group): normal (10 mL/kg, per os (p.o.)), scopolamine (Sco, $1.2 \mathrm{mg} / \mathrm{kg}$, intraperitoneal injection (i.p.)), donepezil (PC, $1 \mathrm{mg} / \mathrm{kg}$, p.o.), G. biloba L. leaf (GL, $40 \mathrm{mg} / \mathrm{kg}$, p.o.), H. erina- ceus (Bull.) Pers. fruit (HE, $200 \mathrm{mg} / \mathrm{kg}$, p.o.), and a mixture of $\mathrm{GL}$ and $\mathrm{HE}(\mathrm{GH}, 240 \mathrm{mg} / \mathrm{kg}$, p.o.). All samples were dissolved in $0.9 \%$ saline and administered for 1 week. Afterward, each group was induced with $1.2 \mathrm{mg} / \mathrm{kg}$ scopolamine (dissolved in $0.9 \%$ saline) $30 \mathrm{~min}$ before Y-maze and NORT tests on the first day. Body weight was measured once weekly from day 0 and did not change among groups (Figure 1S). The Y-maze ( $n=5$ per group) and novel objective recognition task (NORT ( $n=5$ per group)) were performed from day 7 to day 8 (see Figure $1(\mathrm{a})$ ) $[32,33]$. After behavior tests, all mice ( $n=10$ per group) were sacrificed and collected whole brain and then analyzed for histology ( $n=3$ per group) and biochemical assessments ( $n=7$ per group). This in vivo study was carried out according to the Guide for the Care and Use of Laboratory Animals and approved by the Institutional Animal Care and Use Committee of Gachon University, Korea (Approval No. GIACUC-R2019001-2). In addition, all behavior tests were analyzed by using SMART $3.0^{\circledR}$ video tracking software (Panlab, Barcelona, Spain).

2.9. Y-Maze Test. The Y-maze is a maze of three identical arms $\left(60 \times 15 \times 12 \mathrm{~cm}^{3}\right)$. Each arm was marked as A, B, and C. Each mouse was placed in the center of this tool, and the sequence (e.g., $\mathrm{ABC}$ ) and the numbers of arm entries were manually recorded through video analysis. In this behavior test, the actual alternation was defined as entries into arms on consecutive choices (i.e., $\mathrm{ABC}, \mathrm{BCA}$, or $\mathrm{BAC}$ but not ACA). This tool was cleaned using $70 \%$ ethanol. The percentage of spontaneous alternation performance (\%) was calculated by using equation (1) [32]:

$\frac{[\text { Actual alternations (total alternations) }]}{[\text { Possible alternation (total number of arm entries }-2)]} \times 100$.

2.10. Novel Object Recognition Task (NORT) Test. The NORT test was performed using an open field box $\left(60 \times 60 \times 60 \mathrm{~cm}^{3}\right)$. Each mouse was placed in the box with two different objects for $3 \mathrm{~min}$ on the $1^{\text {st }}$ day of training. The next day, mice were placed in the box again in which one of the identical objects had been replaced with a novel object. The exploration time of familiar and novel objects was recorded.

2.11. Acetylcholine (ACh) and Acetylcholinesterase (AChE) Activity Assay. After the behavioral tests, each mouse group was sacrificed, and the brain was collected and stored at $-80^{\circ} \mathrm{C}$. Before the ACh and AChE activity assay, whole brain ( $n=7$ per group) with PBS (Ca. 20-fold volumes) buffer was homogenized using an MP FastPrep-24 Instrument (MP Biomedicals Inc., SA, USA). The homogenates in PBS were centrifuged at $12,000 \times g$ for $30 \mathrm{~min}$ at $4^{\circ} \mathrm{C}$. The upper solution was used for ACh and AChE activity. The amount of brain lysate solution was calculated using the Bio-Rad Bradford kit (Bio-Rad).

ACh levels were analyzed using an EnzyChrom ${ }^{\mathrm{TM}}$ acetylcholine assay kit (BioAssay System, CA, USA). Briefly, $20 \mu \mathrm{L}$ of brain lysate solution was mixed with $80 \mu \mathrm{L}$ working 


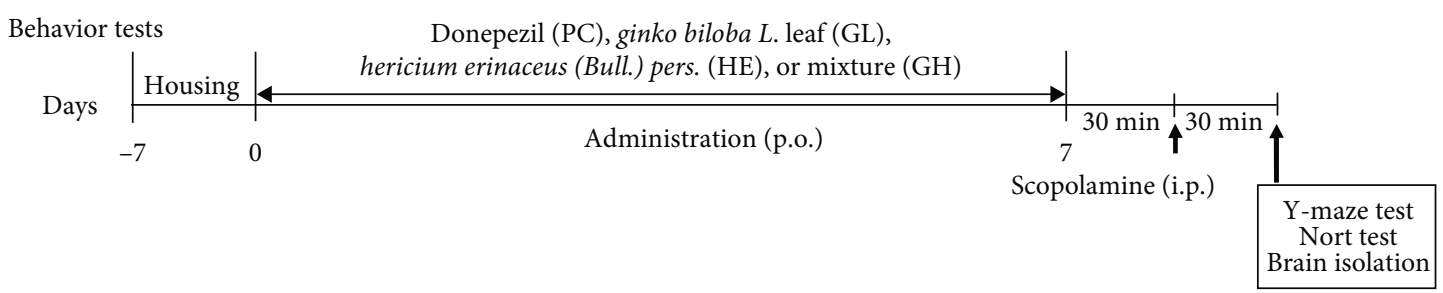

(a)

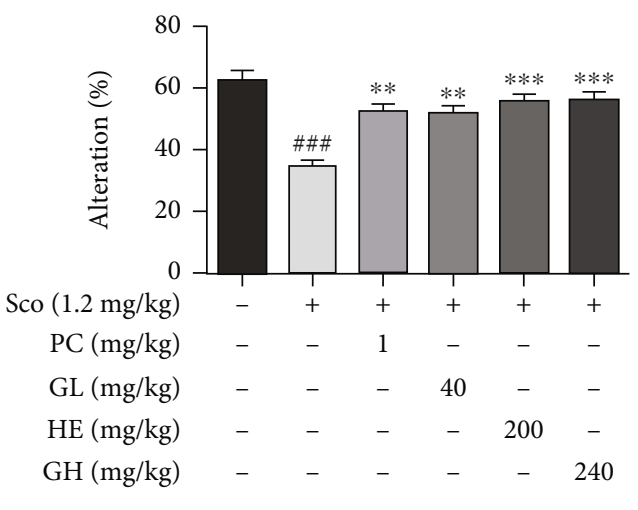

(b)

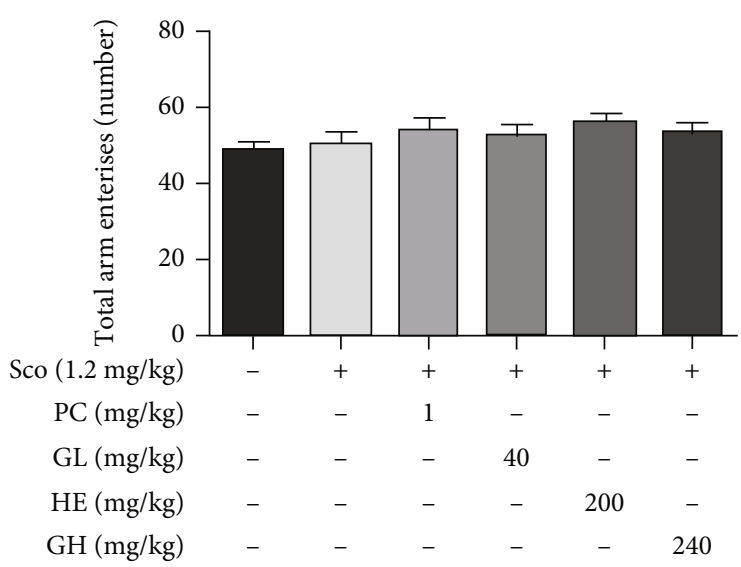

(c)

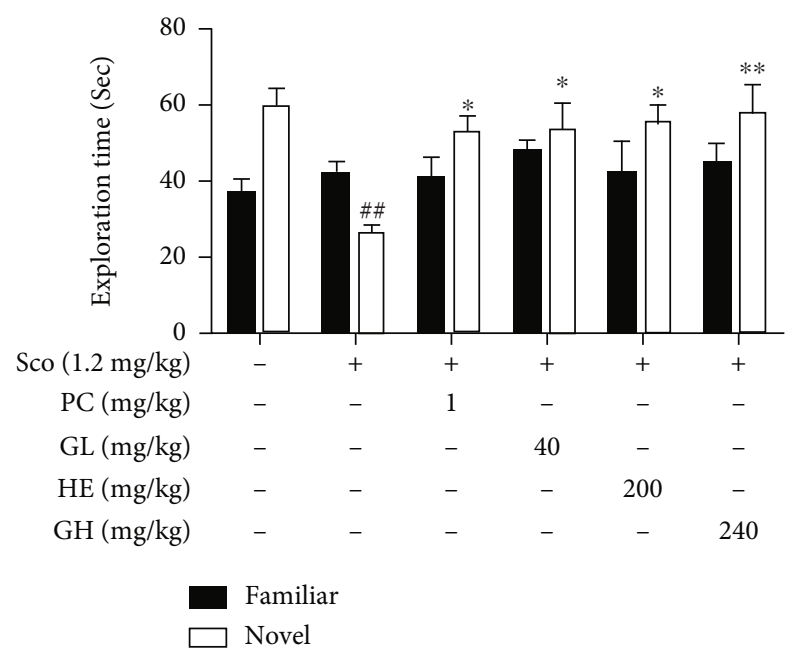

(d)

Figure 1: Effect of the mixture (GH) of Ginkgo biloba L. leaf (GL) and Hericium erinaceus (Bull.) Pers. (HE) fruit extracts on scopolamine(Sco-) induced mouse model. (a) In vivo experiments were performed as shown in the schematic diagram. Each group was orally administered with GH (240 mg/kg), GL (40 mg/kg), HE (200 mg/kg), PC (1 mg/kg donepezil), or water. Before behavior tests (30 min), Sco was intraperitoneally injected for constructing the memory deficit model. (b, c) The Y-maze test was performed 30 min later. Spontaneous alternation percentage (b) and total numbers of arm entries (c) were recorded. (d) NORT test was performed 30 min later. The exploration times of the familiar and novel objects were recorded. Each group was orally administered with GH (240 mg/kg), GL $(40 \mathrm{mg} / \mathrm{kg}), \mathrm{HE}(200 \mathrm{mg} / \mathrm{kg})$, PC (1 mg/kg donepezil), or water. Before behavior tests (30 min), Sco was intraperitoneally injected for constructing the memory deficit model. All behavior tests were analyzed by using video tracking software. Each behavior represents the mean \pm SEM $(n=4-5) .{ }^{\#} P<0.05$ and ${ }^{\# \#} P<0.01$ vs. control group. ${ }^{* *} P<0.01$ and $^{* * *} P<0.001$ vs. Sco-treated group.

reagent in a 96-well plate. The color intensity was detected using a microplate reader (Bio-Rad) at $570 \mathrm{~nm}$ from $0 \mathrm{~min}$ to $10 \mathrm{~min}$, compared with that of the standard (ACh) [34].

AChE activity was analyzed using the QuantiChrom ${ }^{\mathrm{TM}}$ Acetylcholinesterase Assay Kit (BioAssay System). The AChE assay was conducted in a 96-well plate, and $10 \mu \mathrm{L}$ of brain lysate solution was mixed with a $190 \mu \mathrm{L}$ working reagent in a 96-well plate. The intensities of samples were detected using a microplate reader (Bio-Rad) at $412 \mathrm{~nm}$ from $0 \mathrm{~min}$ to $10 \mathrm{~min}$ [34]. AChE activity of each group was calculated as the percentage, compared to the control group.

2.12. Western Blotting Assay. SH-SY5Y cells or brain tissues ( $n=7$ per group) were lysed in PRO-PREP ${ }^{\mathrm{TM}}$ buffer 
(iNtRON Biotechnology, Seongnam, Korea) to obtain proteins. The protein amount from each sample was calculated using the Bio-Rad Bradford kit (Bio-Rad). An equal amount $(30 \mu \mathrm{g})$ of protein was loaded and separated using $10-12 \%$ SDS-PAGE gel and transferred onto a nitrocellulose membrane (Millipore Corp., MA, USA). Blocking was performed with $5 \%$ skimmed milk for $2 \mathrm{~h}$, and the blots were incubated for $1 \mathrm{~d}$ with primary antibodies against Bax, Bcl-2, cleavedcaspase-3, BDNF, CREB, pCREB, ERK, pERK, AKT, pAKT, GSK $3 \beta$, pGSK $3 \beta$, and GAPDH (dilution $1: 1000$ ). The blots were then incubated with secondary antibodies (dilution, $1: 2000)$. Protein bands were analyzed using the Chemi Doc$\mathrm{XRS}^{+}$imaging system (Bio-Rad).

2.13. Histopathological Analysis. We obtained whole mouse brain by carrying out perfusion for blood removal according to a previous study [27]. Brain tissues ( $n=3$ per group) were collected from all groups and then fixed in $10 \%$ formalin. Fixed tissues were processed to obtain $4 \mu \mathrm{m}$ paraffinembedded sections. Each section was stained with hematoxylin and eosin (H\&E) and analyzed at 4-40x magnification using a microscope (Olympus, Tokyo, Japan). The optical density of H\&E-stained tissue sections in the dentate gyrus (DG), cornu ammonis 1 (CA1), and cornu ammonis $2 / 3$ $(\mathrm{CA} 2 / 3)$ regions was analyzed using the ImageJ software (Bethesda, MD, USA).

2.14. Immunohistochemistry Analysis. The obtained $4 \mu \mathrm{m}$ paraffin-embedded sections ( $n=3$ per group) were deparaffinized using xylene and rehydrated with $\mathrm{EtOH}$ (100\%, 90\%, $80 \%$, and $70 \%$ ), followed by treatment with an endogenous peroxidase blocker, and finally washed with PBS. These sections were incubated with the primary antibody, BDNF (dilution $1: 500$ ), at $4^{\circ} \mathrm{C}$. After washing in PBS, each section was incubated with a biotinylated anti-goat and anti-rabbit IgG (dilution $1: 200$ ) for $1 \mathrm{~h}$ and then with avidin-biotin horseradish peroxidase complex (Vector Laboratories, CA, USA). The optical density of BDNF immunoreactivity in the CA1 and CA2/3 regions was analyzed using ImageJ software. The images were photographed at 4-40x magnification using a microscope (Olympus).

2.15. Statistical Analysis. In this study, all data were analyzed using GraphPad Prism 5 software (CA, USA) and represented as means \pm standard error of the mean (SEM). All results were analyzed using one-way analysis of variance (ANOVA), followed by Tukey-Kramer's $t$-test for post hoc analysis. Differences with a $P$ value less than 0.05 were considered statistically significant.

\section{Results}

3.1. GH Improves Neuroprotective Effects on ScopolamineInduced Cytotoxicity in SH-SY5Y Cells. Scopolamine showed cytotoxicity in neuronal cells with cholinergic dysfunction [10]. For studying the cytotoxicity effect of scopolamine in SH-SY5Y cells, the SH-SY5Y cells were treated with 1, 3, or $5 \mathrm{mM}$ scopolamine for 1 day. As shown in Figure 2(a), treatment with $5 \mathrm{mM}$ scopolamine significantly decreased cell viability $\left(63.33 \pm 3.96 \%\right.$, $\left.{ }^{\# \# \# ~} P<0.001\right)$ compared to that of the control group. Therefore, further tests were performed using $5 \mathrm{mM}$ scopolamine to investigate the neuroprotective effects of $\mathrm{GH}$ on scopolamine-induced cytotoxicity. In addition, GH was mixed with GL and $\mathrm{HE}$ in a $1: 5$ ratio, since the cytotoxicity of GL and $\mathrm{HE}$ on scopolamine-induced $\mathrm{SH}$ SY5Y cells was significantly suppressed at $50 \mu \mathrm{g} / \mathrm{mL}$ (GL, $22.02 \pm 5.14 \%,{ }^{*} P<0.05$ ) and $250 \mu \mathrm{g} / \mathrm{mL}(\mathrm{HE}, 24.82 \pm 2.28$ $\left.\%,{ }^{* *} P<0.001\right)$, respectively. SH-SY5Y cells were pretreated with 50,100 , and $250 \mu \mathrm{g} / \mathrm{mL} \mathrm{GH}$ for $1 \mathrm{~h}$ and then cotreated with $5 \mathrm{mM}$ scopolamine for $24 \mathrm{~h}$. In the MTT assay, GH significantly increased cell viability compared with that in the negative (scopolamine only) group (Figure 2(b)). Moreover, the MTT assay showed that GH did not exert any cytotoxicity. As shown in Figure 2(b), the treatment of scopolamine progressively changed the cellular morphology such as shrinkage of cells and decreased density of cells. Meanwhile, pretreatment with $250 \mu \mathrm{g} / \mathrm{mL}$ GH prevented the observed situation. These results suggest that $\mathrm{GH}$ prevented scopolamine-induced cytotoxicity.

3.2. Phytochemical Analysis of GH by Using HPLC System. In our study, we analyzed several components from GH mixture extract. As shown in Table 1 and Figure 3S-5S, GH mixture mainly involved ginkgolide A $(12.632 \pm 0.605 \mathrm{mg} /$ g), ginkgolide B $(4.846 \pm 0.538 \mathrm{mg} / \mathrm{g})$, quercetin $(7.693 \pm 0.741 \mathrm{mg} / \mathrm{g})$, and hericene A $(1.669 \pm 0.030 \mathrm{mg} / \mathrm{g})$. In addition, other components as kaempferol, hericene $\mathrm{D}$, isorhamnetin, and acacetin were detected for $0.591 \pm 0.029$ $\mathrm{mg} / \mathrm{g}, 0.578 \pm 0.005 \mathrm{mg} / \mathrm{g}, 0.026 \pm 0.002 \mathrm{mg} / \mathrm{g}$, and 0.0030 $\pm 0.0001 \mathrm{mg} / \mathrm{g}$, respectively.

3.3. GH Prevents the Scopolamine-Induced ROS, Mitochondrial Dysfunction, and Apoptosis Pathways in SHSY5Y Cells. To evaluate whether GH-treated neuroprotective effects were regulated via the suppression of apoptosis pathways, we first measured ROS production in SH-SY5Y cells. The scopolamine-treated group (445.60 $\pm 6.29 \%$, $\left.{ }^{\# \# \# ~} P<0.001\right) \quad$ showed a significant increase in ROS production compared with that in the control group, as shown in Figure 3(a). In addition, we measured the protection of mitochondrial dysfunction as a major hallmark of apoptosis in SH-SY5Y cells (Figure 3(b)). The scopolamine-treated group $(60.20 \pm 1.18 \%$, \#\# $P<0.01)$ demonstrated a significant loss in mitochondrial membrane potential, whereas $\mathrm{GH}$-treated groups significantly recovered the loss of mitochondrial membrane potential in a dose-dependent manner. In particular, the scopolamine-treated group $\left({ }^{\# \#} P<0.001\right)$ showed increased levels of apoptosis-related proteins as the Bax/ Bcl-2 ratio and cleaved-caspase-3, while $\mathrm{GH}$-treated groups showed a significant decrease in the protein levels (Figures 4(c) and 4(d)). These results indicated that $\mathrm{GH}$ has a neuroprotective effect by reducing ROS production and mitochondrial dysfunction and suppressing the apoptosis pathways.

3.4. GH Increases the Levels of BDNF and Activates GSK3 $\beta$, ERK, and CREB Signaling Pathways in ScopolamineInduced SH-SY5Y Cells. To investigate the neuronal 


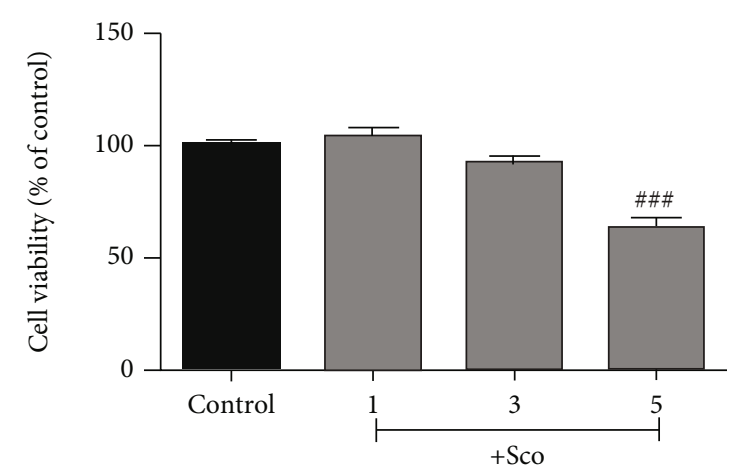

Concentration $(\mathrm{mM})$
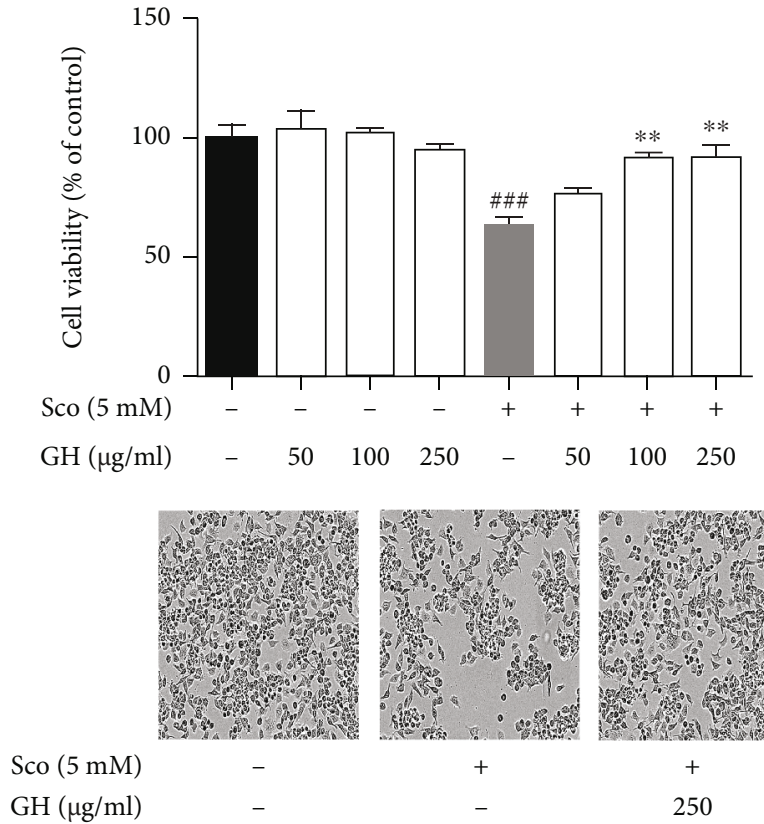

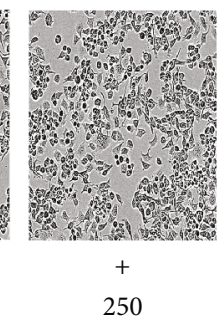

(b)

Figure 2: Effect of the mixture (GH) of Ginkgo biloba L. leaf (GL) and Hericium erinaceus (Bull.) Pers. (HE) fruit extracts on scopolamine(Sco-) induced cytotoxicity in human neuroblastoma (SH-SY5Y) cells. (a) Cells were treated with Sco at 1, 3, and $5 \mathrm{mM}$ concentrations. Cell viability was measured by MTT assay. (b) Cells were pretreated with 50,100, and $500 \mu \mathrm{g} / \mathrm{mL} \mathrm{GH}$ for $1 \mathrm{~h}$ and then cotreated with $5 \mathrm{mM}$ Sco cotreated for $24 \mathrm{~h}$. Cell viability was measured by MTT assay. Morphological images of cells were observed by using a microscope (scale bar $=50 \mu \mathrm{m})$. Data represent the mean $\pm \operatorname{SEM}(n=3) .{ }^{\# \# \#} P<0.001$ vs. control group. ${ }^{* *} P<0.01$ vs. Sco-treated group.

TABLE 1: Contents of hericene A, hericene $\mathrm{D}$, ginkgolide $\mathrm{A}$, ginkgolide $\mathrm{B}$, isorhamnetin, acacetin, quercetin, and kaempferol compounds by HPLC analysis in the presence of GH mixture.

\begin{tabular}{lcccccccc}
\hline \multirow{2}{*}{ Samples } & & \multicolumn{2}{c}{ Content $(\mathrm{mg} / \mathrm{g})$} \\
& Hericene A & Hericene D & Ginkgolide A & Ginkgolide B & Isorhamnetin & Acacetin & Quercetin & Kaempferol \\
\hline GH mixture & $1.669 \pm 0.030$ & $0.578 \pm 0.005$ & $12.632 \pm 0.605$ & $4.846 \pm 0.538$ & $0.026 \pm 0.002$ & $0.0030 \pm 0.0001$ & $7.693 \pm 0.741$ & $0.591 \pm 0.029$
\end{tabular}

Data represent the mean $\pm \operatorname{SEM}(n=3)$.

protection pathways in scopolamine-induced SH-SY5Y cells, we confirmed the signal transduction pathways (e.g., cell survival, growth, and proliferation), including BDNF, GSK3 $\beta$, CREB, and ERK signaling (Figure 4). Our data revealed that scopolamine significantly decreased BDNF, pGSK $3 \beta$, pCREB, and pERK, whereas GH treatment inhibited the effects of scopolamine on the levels of pGSK $3 \beta$, pCREB, and pERK. It was reported that BDNF, GSK $3 \beta$, $\mathrm{CREB}$, and ERK signaling play vital roles in the process of memory, learning, and modulation of cholinergic function, suggesting that $\mathrm{GH}$ has a neuroprotective effect via regulation of these signaling pathways [12].

3.5. GH Improves Scopolamine-Induced Memory Impairment in Behavior Tests. For elucidating the neuroprotective effects of $\mathrm{GH}$ on cognitive memory function, we carried out two behavior tests on the scopolamine-induced mouse model: Y-maze and NORT tests (Figure 1(a)). The mouse model used was six-week-old ICR males and was orally administered GL (40 mg/kg, p.o.), HE (200 mg/kg, p.o.), or GL+HE $(\mathrm{GH}, 240 \mathrm{mg} / \mathrm{kg}$, p.o.) for 7 days before scopolamine injection $(1.2 \mathrm{mg} / \mathrm{kg}$, i.p.). In particular, the administration dose of $\mathrm{GH}$ was also mixed with $\mathrm{GL}$ and $\mathrm{HE}$ in a 1:5 ratio as shown in vitro data, and the administration dose of GL was referred from previous findings $[35,36]$. In addition, the positive control was used donepezil ( $1 \mathrm{mg} / \mathrm{kg}$, p.o.), which is used for treating AD.

In the Y-maze test, each group was allowed to explore the Y-maze for $8 \mathrm{~min}$, and the spontaneous alternation percentage and total number of arm entries were recorded. The spontaneous alternation percentage in the scopolamine $(1.2 \mathrm{mg} / \mathrm{kg}$, i.p.)-treated mice group was critically decreased $(35.09 \pm 6.27 \%$, \#\# $P<0.01)$ than that of the normal group $(62.38 \pm 3.47 \%)$ (Figure 1(b)). The decreased spontaneous alternation by scopolamine was significantly improved by treatment with $240 \mathrm{mg} / \mathrm{kg} \mathrm{GH}\left(56.36 \pm 2.35 \%,{ }^{* *} P<0.01\right)$. Interestingly, it was observed that the spontaneous alternation by $\mathrm{GH}$ treatment was higher than that in the other groups $(40 \mathrm{mg} / \mathrm{kg} \mathrm{GL}, 52.09 \pm 2.42 \% ; 200 \mathrm{mg} / \mathrm{kg} \mathrm{HE}, 55.64$ $\pm 2.11 \%$; and $1 \mathrm{mg} / \mathrm{kg}$ PC (donepezil), $53.02 \pm 2.55 \%$ ), implying that there was a synergistic effect of GH administration on enhancing memory function. In addition, the difference in the number of total entries did not impact the results of the Y-maze (Figure $1(\mathrm{c})$ ). 


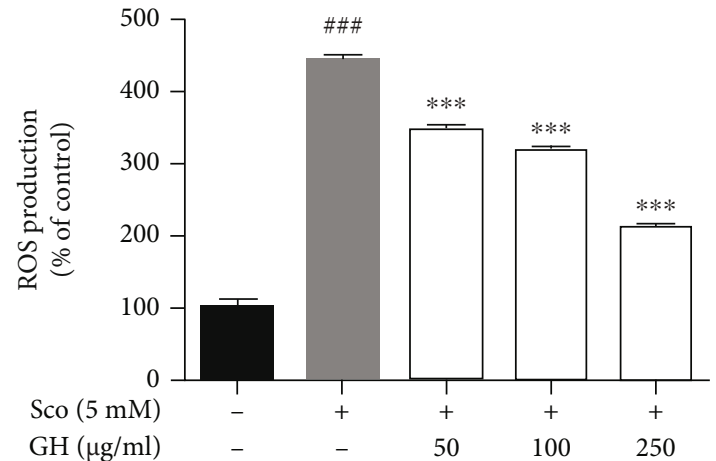

(a)

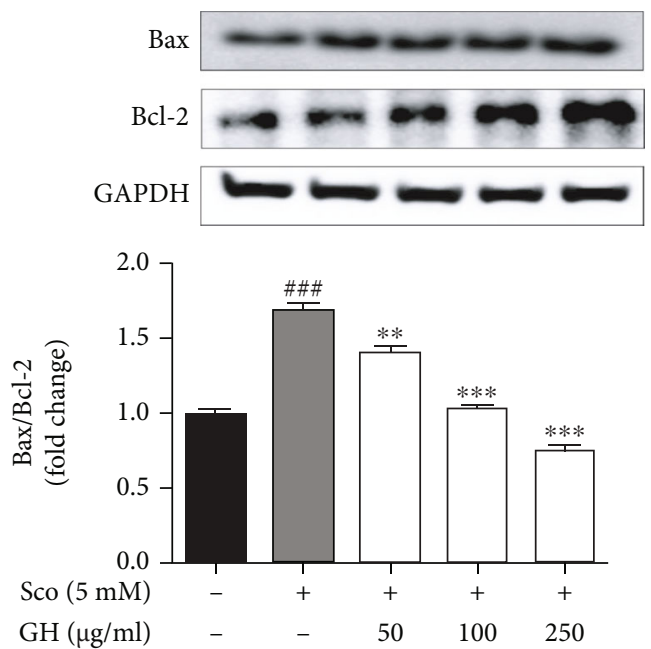

(c)

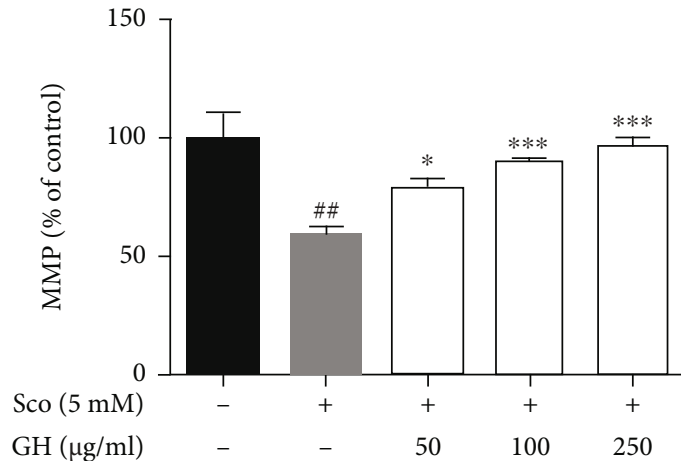

(b)

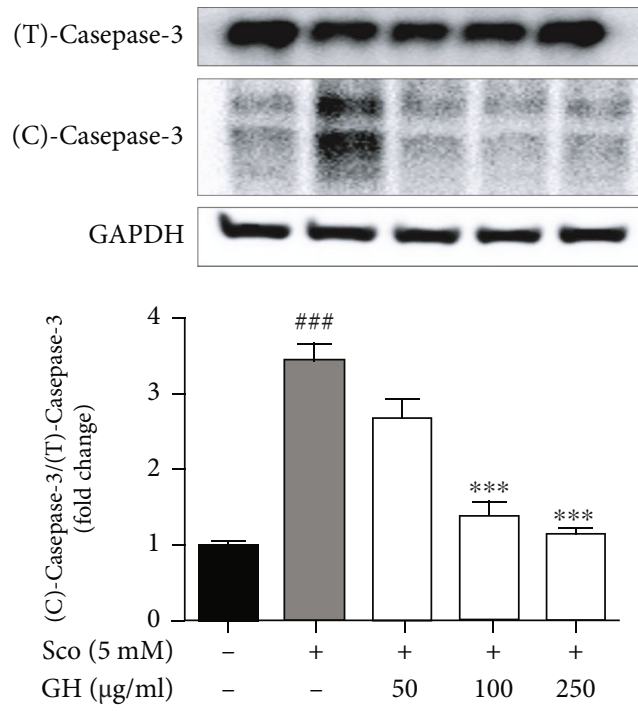

(d)

Figure 3: Effect of the mixture (GH) of Ginkgo biloba L. leaf (GL) and Hericium erinaceus (Bull.) Pers. (HE) fruit extracts on scopolamine(Sco-) induced ROS production, mitochondrial dysfunction, and apoptosis pathways in human neuroblastoma (SH-SY5Y) cells. (a) ROS production was measured using the DCF-DA staining assay. (b) Mitochondrial membrane potential was measured for evaluating mitochondrial dysfunction using the JC-10 assay kit. (c, d) Western blotting assay of Bax, Bcl-2, cleaved- (C-) caspase-3, and total- (T-) caspase-3 was performed, with GAPDH as a loading control. Quantification was calculated using densitometric analysis using Bio-Rad Quantity software. Data represent the mean $\pm \operatorname{SEM}(n=3)$. ${ }^{\# \#} P<0.01$ and ${ }^{\# \# \#} P<0.001$ vs. control group. ${ }^{* *} P<0.01$ and ${ }^{* * *} P<0.001$ vs. Sco-treated group.

The role of GH on cognitive memory was also assessed using the NORT test. The scopolamine group $(26.48 \pm 1.97 \mathrm{sec}, \# \#<0.01)$ showed a significant decrease in exploration in novel places, compared with that in the normal group $(59.86 \pm 4.95 \mathrm{sec})$. Meanwhile, the administration of $240 \mathrm{mg} / \mathrm{kg} \mathrm{GH}\left(57.78 \pm 9.54 \mathrm{sec},{ }^{* *} P<0.01\right)$ significantly increased the exploration time at novel places compared to that in the $1 \mathrm{mg} / \mathrm{kg}$ PC group $\left(53.47 \pm 3.84 \mathrm{sec},{ }^{*} P<0.05\right)$. Indeed, the exploring time was significantly higher for the $240 \mathrm{mg} / \mathrm{kg} \mathrm{GH}-, 200 \mathrm{mg} / \mathrm{kg}$ HE $\quad\left(55.50 \pm 4.49,{ }^{*} P<0.05\right)-, \quad 1 \mathrm{mg} / \mathrm{kg} \quad$ PC $\left(53.47 \pm 3.84 \mathrm{sec},{ }^{*} P<0.05\right)-, \quad$ and $\quad 40 \mathrm{mg} / \mathrm{kg} \quad \mathrm{GL}$ $\left(53.80 \pm 8.74 \mathrm{sec},{ }^{*} P<0.05\right)$-treated groups compared with that in the scopolamine group, respectively (Figure 1(d)).

3.6. GH Restores the ACh Level and AChE Activity in the Scopolamine-Induced Mouse Brain. The ACh level and AChE activity in the mouse brain lysates were measured using respective assay kits [34]. As shown in Figure 5(a), our data revealed that the ACh level in the brain was markedly decreased in the scopolamine-induced group $(27.98 \pm 2.16 \mathrm{nmol} / \mathrm{mg}$ protein, \#\#\# $P<0.01)$ than that in normal mice (49.92 $\pm 1.81 \mathrm{nmol} / \mathrm{mg}$ protein). The ACh content of the GH group $(41.55 \pm 1.83 \mathrm{nmol} / \mathrm{mg}$ protein $)$ was higher than that of the scopolamine group. Meanwhile, AChE activity was significantly higher in the scopolamine group $(340.68 \pm 32.91 \%$, \#\#\# $P<0.001)$ than that in the normal group $(100.00 \pm 11.57 \%)$, but the $\mathrm{GH}$ group $\left(191.37 \pm 31.63 \%,{ }^{* *} P<0.01\right)$ showed that AChE activity was markedly decreased as similar to that in the PC group $\left(214.17 \pm 18.80 \%,{ }^{*} P<0.05\right)$ (Figure 5(b)).

3.7. GH Modulates the BDNF/ERK/CREB Pathways in the Mouse Brain. To evaluate the related molecular mechanisms underlying the neuroprotective effects of $\mathrm{GH}$, the protein levels of BDNF, pAKT, pERK, and pCREB in the mouse 

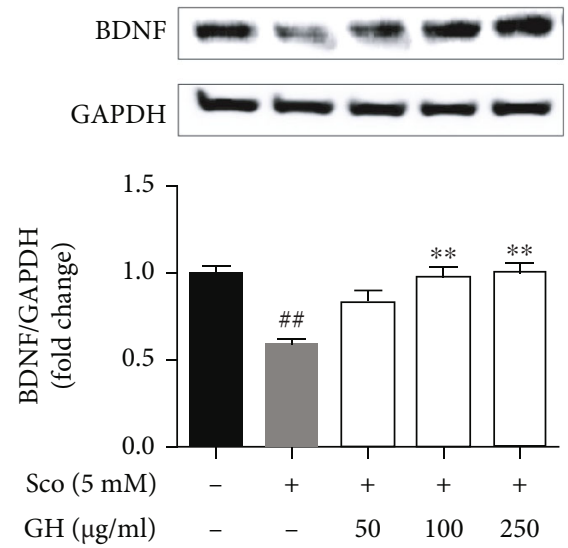

(a)
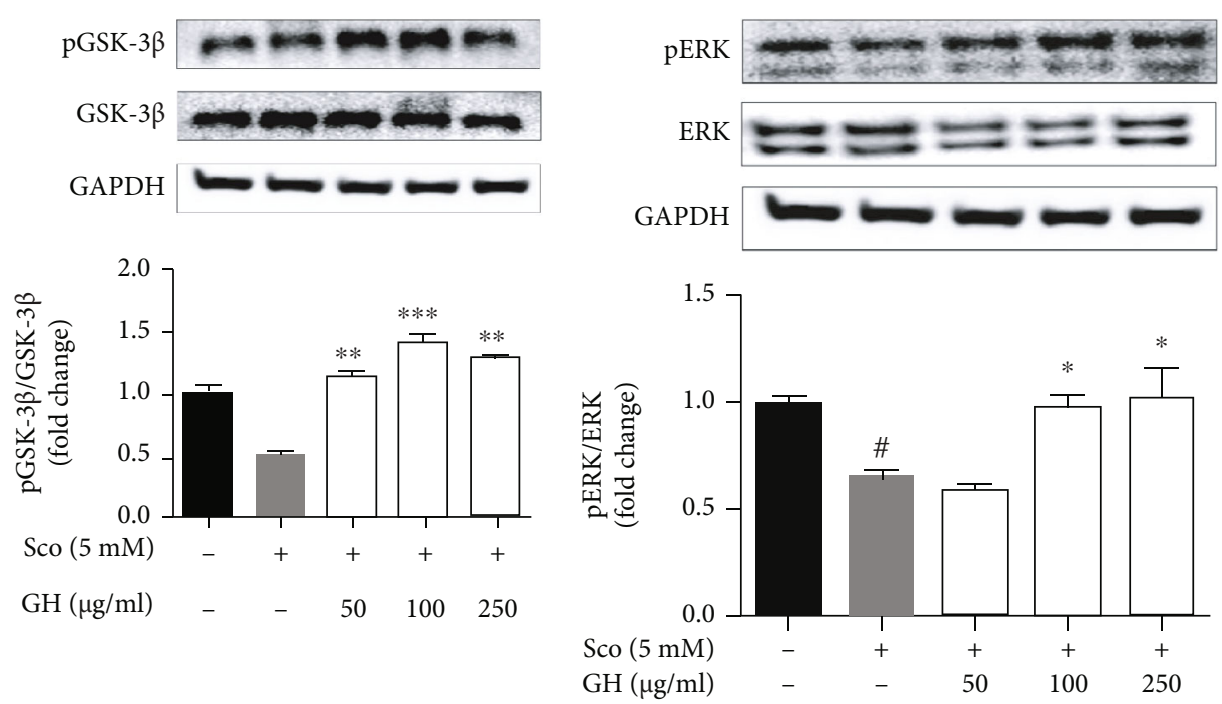

(b)

(c)

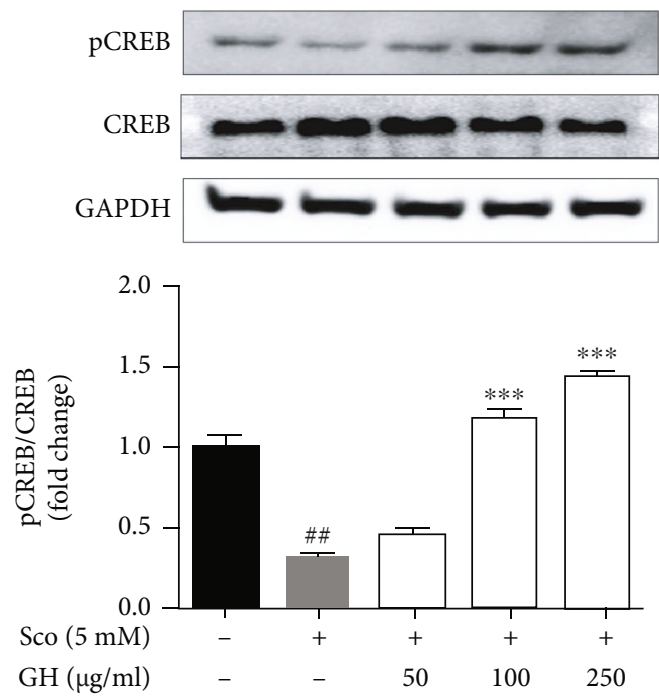

(d)

Figure 4: Neuronal protective effect of the mixture (GH) of Ginkgo biloba L. leaf (GL) and Hericium erinaceus (Bull.) Pers. (HE) fruit extracts on scopolamine- (Sco-) induced SH-SY5Y neuroblastoma cells. (a-d) Western blotting assay of BDNF (a), pGSK3 $\beta /$ GSK3 $\beta$ (b), pERK/ERK (c), and pCREB/CREB (d) was carried out. GAPDH was used as a loading control. Quantification was calculated using densitometric analysis using Bio-Rad Quantity software. Data represent the mean $\pm \operatorname{SEM}(n=3)$. ${ }^{\#} P<0.05$ and ${ }^{\# \#} P<0.01$ vs. control group. ${ }^{*} P<0.05,{ }^{* *} P<0.01$, and ${ }^{* *} P<0.001$ vs. Sco-treated group. 


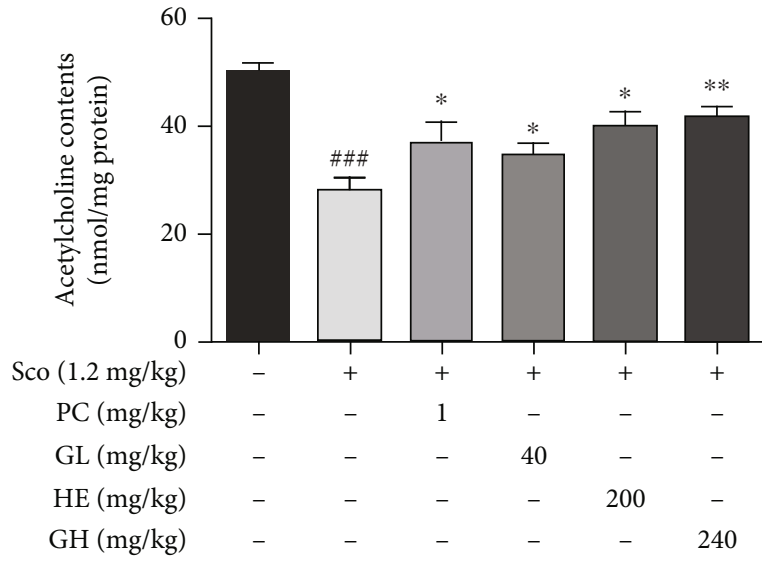

(a)

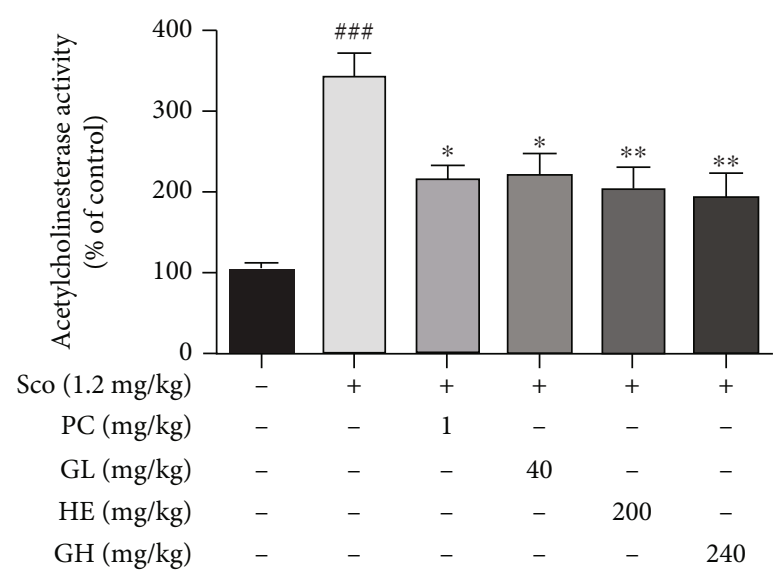

(b)

FIgURe 5: Effect of the mixture (GH) of Ginkgo biloba L. leaf (GL) and Hericium erinaceus (Bull.) Pers. (HE) fruit extracts on acetylcholine (ACh) level and acetylcholinesterase (AChE) activity in the brain. (a) ACh level in the brain lysates. (b) AChE activity in the brain lysates. Data represent the mean $\pm \operatorname{SEM}(n=7)$. ${ }^{\#} P<0.05$ and ${ }^{\# \#} P<0.01$ vs. control group. ${ }^{* *} P<0.01$ and ${ }^{* * *} P<0.001$ vs. Sco-treated group.

brain lysates were confirmed (Figure 6). The scopolamine group ( $\left.{ }^{\# \# \# ~} P<0.001\right)$ significantly decreased the expression level of BDNF in the mouse brain, but GH administration $\left({ }^{* * *} P<0.01\right)$ significantly reversed it (Figure $\left.6(\mathrm{a})\right)$. In addition, the expression levels of pAKT in the GH group $\left({ }^{* *} P<0.001\right)$ were higher than that in the other groups (Figure 6(b)). Moreover, GH administration significantly increased the scopolamine-induced pERK $\left({ }^{* * *} P<0.001\right)$ and pCREB $\left({ }^{* *} P<0.001\right)$ in the mouse brain (Figures 6(c) and 6(d)). This indicates that GH improves the scopolamine-induced decrease in the expression level of BDNF as well as ERK/CREB phosphorylation in the mouse brain, which may be involved in alleviating memory impairment.

3.8. GH Ameliorates the Pathological Changes of Hippocampus in Mouse Brain Tissue. Histopathological changes in the mouse hippocampus were observed by the H\&E staining assay (Figure 7). Neuronal damage was investigated in the dentate gyrus (DG), cornu ammonis (CA) 1, and $\mathrm{CA} 2 / 3$ region of the hippocampus in terms of the number of viable neurons, by using a microscope (40x magnification). The brain sections of normal mice displayed the normal structure of the hippocampus, such as the DG, $\mathrm{CA} 1$, and $\mathrm{CA} 2 / 3$ areas. In the scopolamine group, pyramidal cells of the stratum pyramidalis in the DG, CA1, and CA2/3 regions showed that scopolamine $\left({ }^{\# \#} P<0.001\right)$ caused significant damage in each region of the hippocampus, compared with those of the normal group. However, GH administration revealed a marked reversal of scopolamineinduced cell damage, similar to that by donepezil administration, indicating its neuroprotective potential.

3.9. GH Promotes the BDNF Expression in the Mouse Hippocampus. BDNF, as a biomarker for synaptogenesis and synaptic plasticity, engages memory function by promoting neuronal cell survival and differentiation in hippocampal neurons [37]. In the present study, we examined whether GH mediates synapse formation in the scopolamine-induced hippocampus in mice by detecting the number of immunoreactive neurons in the CA1 and $\mathrm{CA} 2 / 3$ regions. The relative number of BDNF-reactive neurons in the CA1 and CA2/3 regions was significantly higher in both donepezil $\left({ }^{*} P<0.05\right)$ and $\mathrm{GH}$-treated $\left({ }^{* * *} P<0.001\right)$ groups in comparison to that in the normal group (Figure 8). Our data suggest that the administration of $\mathrm{GH}$ may be able to induce the expression of BDNF, which is attributed to memory enhancement.

3.10. Phytochemicals from GH Improves Neuroprotective Effects on Scopolamine-Induced Cytotoxicity in SH-SY5Y Cells. As shown in Figure 9, the neuroprotective effects of phytochemicals as hericene $\mathrm{A}$, hericene $\mathrm{D}$, ginkgolide $\mathrm{A}$, ginkgolide $\mathrm{B}$, isorhamnetin, acacetin, quercetin, and kaempferol identified from GH were measured on scopolamineinduced cytotoxicity in SH-SY5Y cells. All phytochemicals prevented the cytotoxicity induced by scopolamine in a dose-dependent manner, and no cytotoxicity was detected. In particular, ginkgolide $A$, ginkgolide $B$, hericene $A$, and hericene $\mathrm{D}$ mainly prevented the scopolamine-induced cytotoxicity at $20 \mu \mathrm{M}$.

\section{Discussion}

In this study, GH showed the effect of neuron protection on scopolamine-induced SH-SY5Y cells and improved scopolamine-induced cognitive impairments in a mouse model via behavioral tests including Y-maze and NORT. Moreover, we measured the neuroprotective mechanism of $\mathrm{GH}$ via in vitro and in vivo models. Interestingly, $\mathrm{GH}$ increased BDNF expression by activating CREB/ERK phosphorylation and downregulating ROS and AChE activities.

Previous studies on the pharmacological effects of GL and $\mathrm{HE}$ extracts in $\mathrm{GH}$ mixture may partly explain our data $[17,29]$. GL ameliorates learning and memory impairments in animal studies and affects neurotransmitter levels, neuroplasticity, and suppression of the brain edema in clinical studies [15, 18]. HE extract showed great potential in 


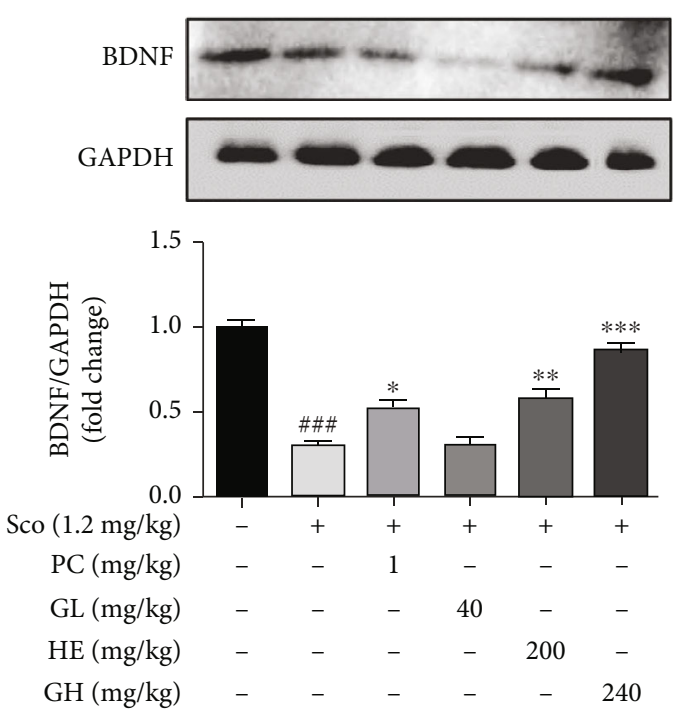

(a)

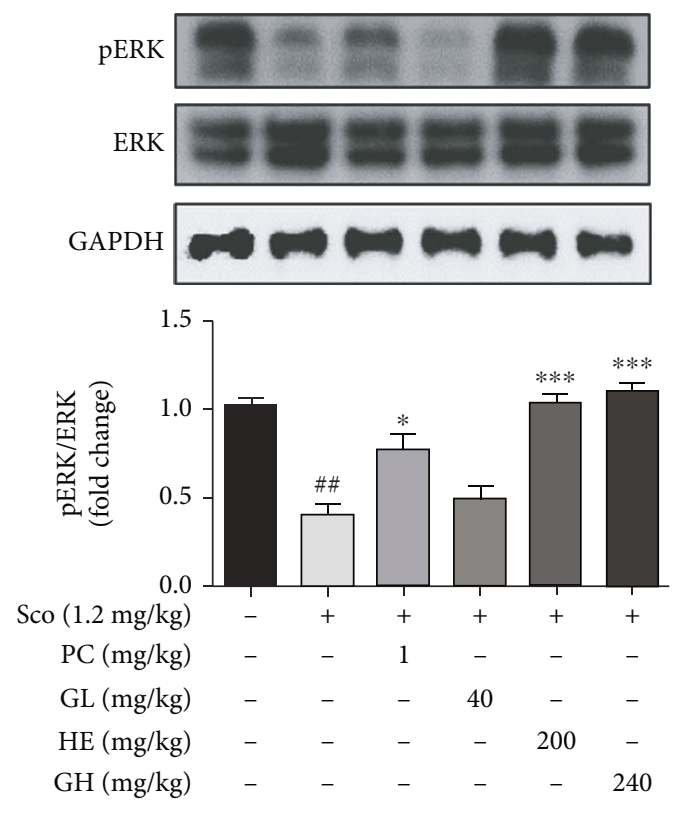

(c)
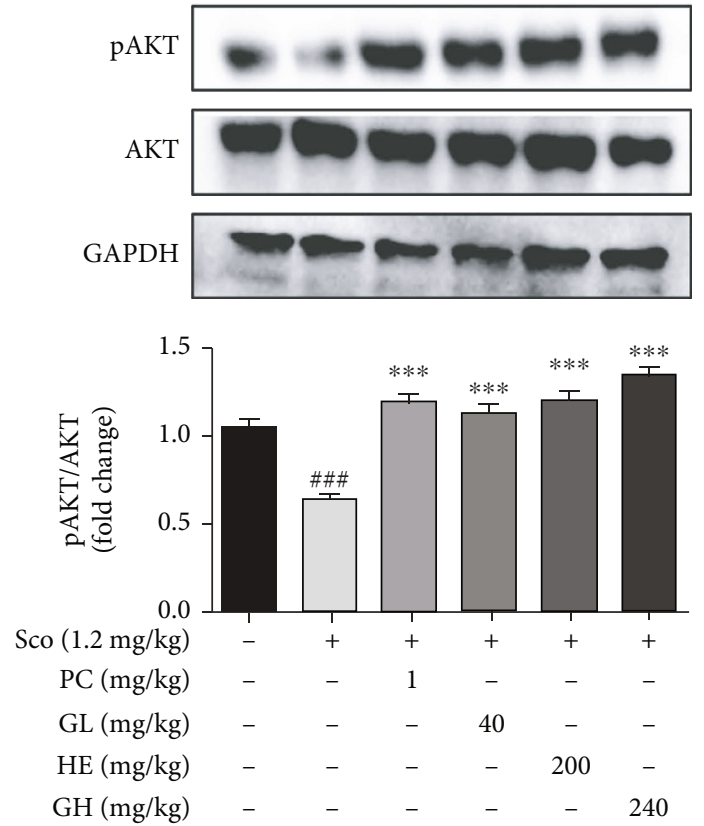

(b)

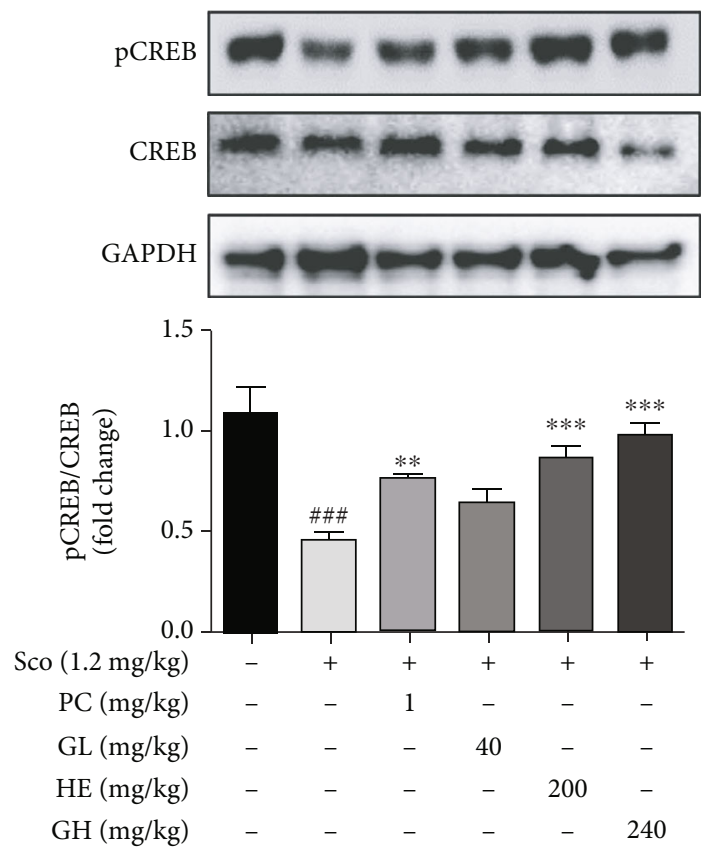

(d)

Figure 6: Effect of the mixture (GH) of Ginkgo biloba L. leaf (GL) and Hericium erinaceus (Bull.) Pers. (HE) fruit extracts on the expressed levels of BDNF, pAKT, pERK, and pCREB in the brain. Whole brain from randomly selected mice in each group was analyzed for western blotting assay. (a-d) Western blotting assay of BDNF (a), pAKT/AKT (b), pERK/ERK (c), and pCREB/CREB (d) was carried out. GAPDH was used as a loading control. Quantification was performed using densitometric analysis with Bio-Rad Quantity software. Data represent the mean $\pm \operatorname{SEM}(n=7) .{ }^{\#} P<0.05$ and $^{\# \#} P<0.01$ vs. control group. ${ }^{* *} P<0.01$ and $^{* * *} P<0.001$ vs. Sco-treated group.

improving the intellectual function of patients with cognitive impairment or against neurodegenerative diseases such as dementia and AD in the previous studies [29-31]. However, there is no report on a mixture of involved GL and HE showing a synergic effect on the scopolamine-induced mouse model. Thus, GL and HE were extracted from raw plant materials and arbitrarily mixed with a ratio of $1: 5$, since GL and HE significantly prevented scopolamineinduced cytotoxicity at 50 and $250 \mu \mathrm{g} / \mathrm{mL}$ concentrations, in scopolamine-induced cytotoxicity, respectively (see Figure 2S). Furthermore, the mixture showed a synergic effect in comparison with each extract of GL or HE extracts on the scopolamine-induced mouse model (Figures 1, 5-8). 


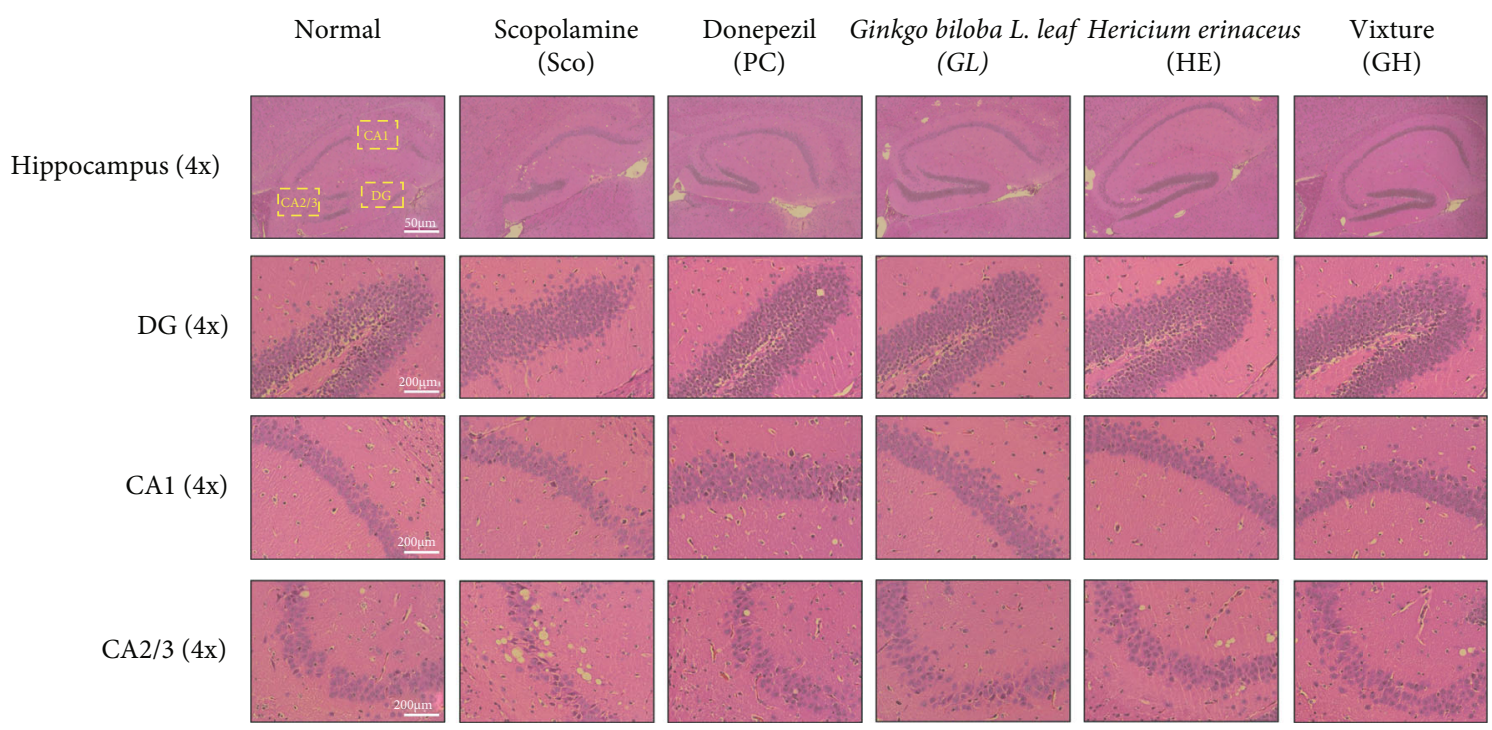

(a)

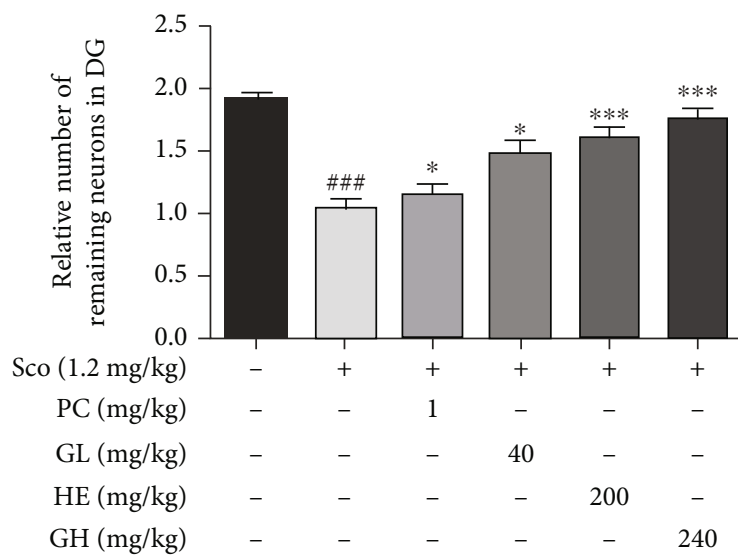

(b)

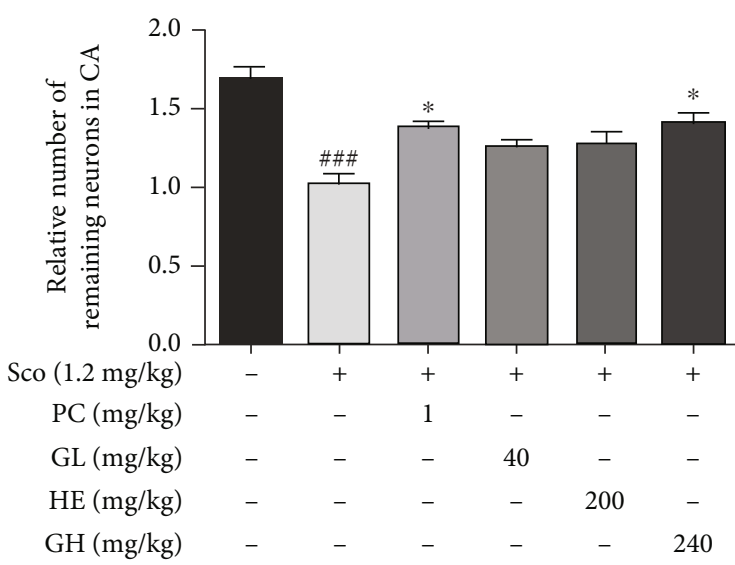

(c)

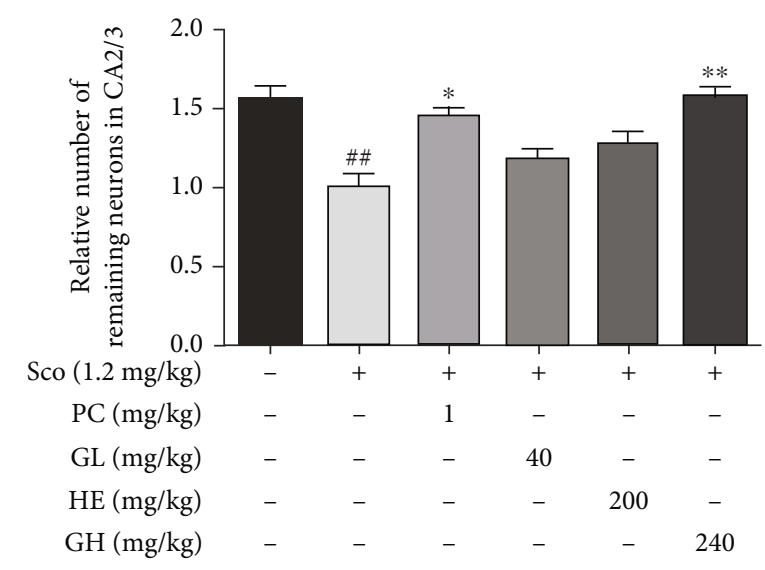

(d)

FIgure 7: Effect of the mixture (GH) of Ginkgo biloba L. leaf (GL) and Hericium erinaceus (Bull.) Pers. (HE) fruit extracts on H\&E staining assay. (a) The morphological changes of DG, CA1, and CA2/3 region from hippocampus. (b-d) The number of live neurons in each region. The area of DG, CA1, and CA2/3 regions was measured and quantified by using Micron (EVOS, v2.0) digital imaging software. Data represent the mean $\pm \operatorname{SEM}(n=3)$. ${ }^{\# \#} P<0.01$ and $^{\# \# \#} P<0.001$ vs. control group. ${ }^{*} P<0.05,{ }^{* *} P<0.01$, and ${ }^{* * *} P<0.001$ vs. Sco-treated group. 


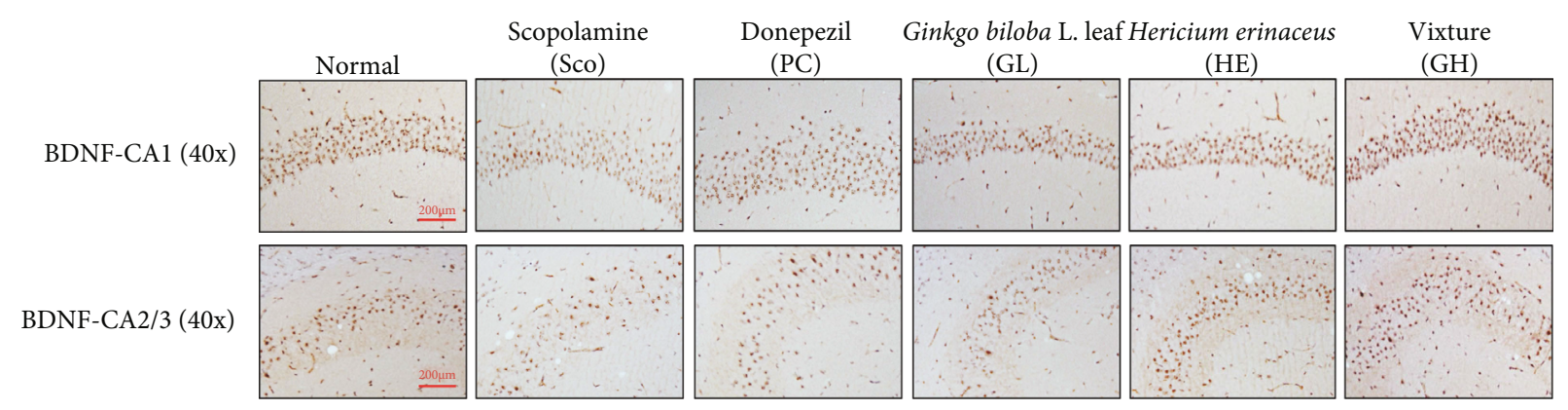

(a)

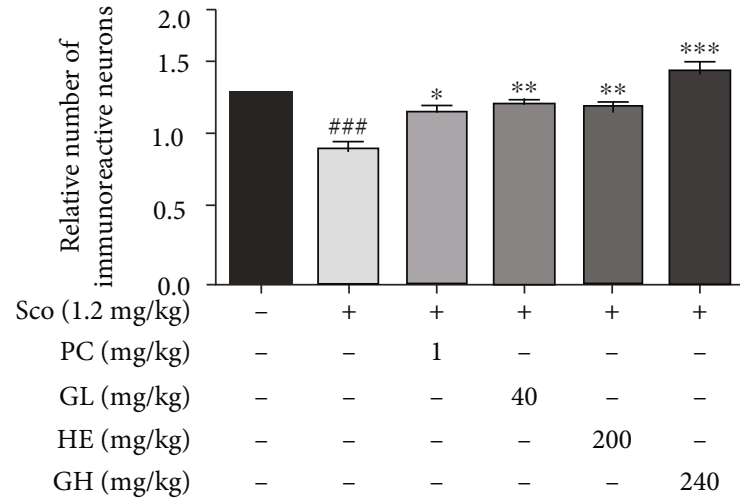

(b)

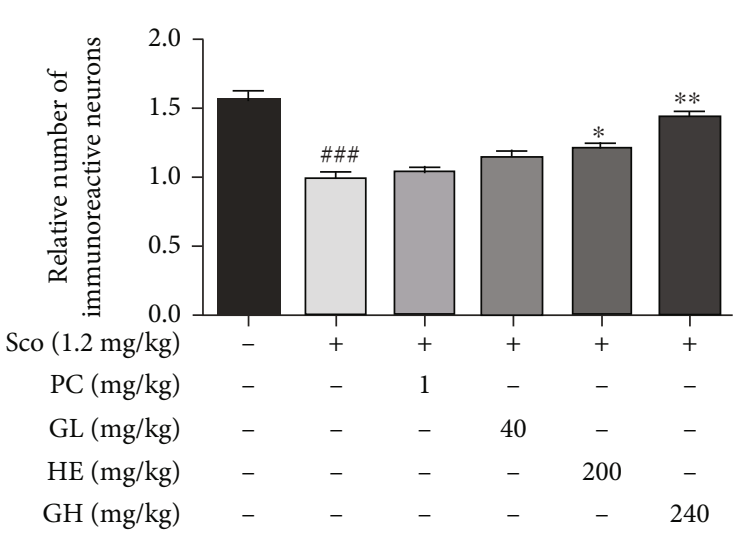

(c)

FIgure 8: Effect of the mixture (GH) of Ginkgo biloba L. leaf (GL) and Hericium erinaceus (Bull.) Pers. (HE) fruit extracts on BDNF immunostaining assay. (a) The morphological changes of CA1 and CA2/3 region from hippocampus. (b, c) The number of live neurons in each region. The area of CA1 and CA2/3 regions was measured and quantified by using Micron (EVOS, v2.0) digital imaging software. Data represent the mean $\pm \operatorname{SEM}(n=3)$. ${ }^{\# \# \#} P<0.001$ vs. control group. ${ }^{*} P<0.05,{ }^{* *} P<0.01$, and ${ }^{* * *} P<0.001$ vs. Sco-treated group.

Scopolamine has been widely used to investigate a model of amnesia in a preclinical study that contributes to increased oxidative stress with impairment of memory and cognitive functions [14]. GH significantly downregulated scopolamine-induced cytotoxicity (Figures 2(b) and 2(c)) and ROS (Figure 3(a) and Figure 6S) and showed greater protection against neuronal cell death (Figure 3). Furthermore, GH suppressed the scopolamine-induced dephosphorylation of GSK $3 \beta$, ERK, and CREB, which play vital roles in cell proliferation and survival signaling pathways (Figure 4). It was revealed that the inhibition of GSK $3 \beta$ by regulating $\mathrm{pAKT}$ reduces neuronal loss by suppressing apoptotic agents [38]. The activation of BDNF, ERK, and CREB signaling is related to neuronal cell survival and proliferation [12, 14]. It seems that the neuronal protection effect of $\mathrm{GH}$ on the scopolamineinduced model may be mainly modulated by BDNF and then activated by CREB and ERK phosphorylation.

In our in vivo results by using behavioral tests (Y-maze test, NORT test), it was found that GH improved scopolamine-induced memory impairments. These scopolamine-induced mouse models are widely used to analyze short-term memory [32]. Donepezil, an AChE inhibitor, is commonly used for treating $\mathrm{AD}$, and it has also been shown to positively affect episodic memory function [39]. Thus, donepezil was used as a positive control in our designed in vivo model. In this study, GH displayed a similar or superior activity to that of donepezil (Figure 1), indicating that GH may be involved in cognitive enhancement.

BDNF affects synaptogenesis and synaptic plasticity in the central nervous system (CNS). Neurotrophic signaling involving ERK, CERB, and AKT is stimulated by the activation of BDNF, which contributes to memory and thinking. Indeed, GH considerably increased the expression levels of pERK, pCREB, and BDNF in the mouse brain (Figure 6), similar to that in in vitro data. Moreover, GL or HE could modulate BDNF/CREB/ERK in the brain and attenuate cognitive deficits in an amnesia mouse model. This indicates that the activation of the BDNF-induced signaling cascade by treating GL and/or HE could have neuroprotective effects on a scopolamine-induced mouse model (Figure 6). Furthermore, GH showed highly immunoreactive neurons by $\mathrm{BDNF}$ in the CA1 and CA2/3 hippocampal regions, indicating that $\mathrm{GH}$ treatment can increase synaptogenesis that is associated with boosting memory function (Figure 8).

Furthermore, the number of neurons observed by staining the doublecortin (DCX) was measured in the DG region of the hippocampus. DCX, a cytoskeletal protein, is expressed through neuronal cells and is widely used as a biomarker for neurogenesis [40]. Scopolamine refers to a decrease in DCX-immunoreactive cells in the DG and damage of dendritic development of the new immature neurons [41]. The decreased levels of stained DCX in the scopolamine-induced group were clearly observed. In the 


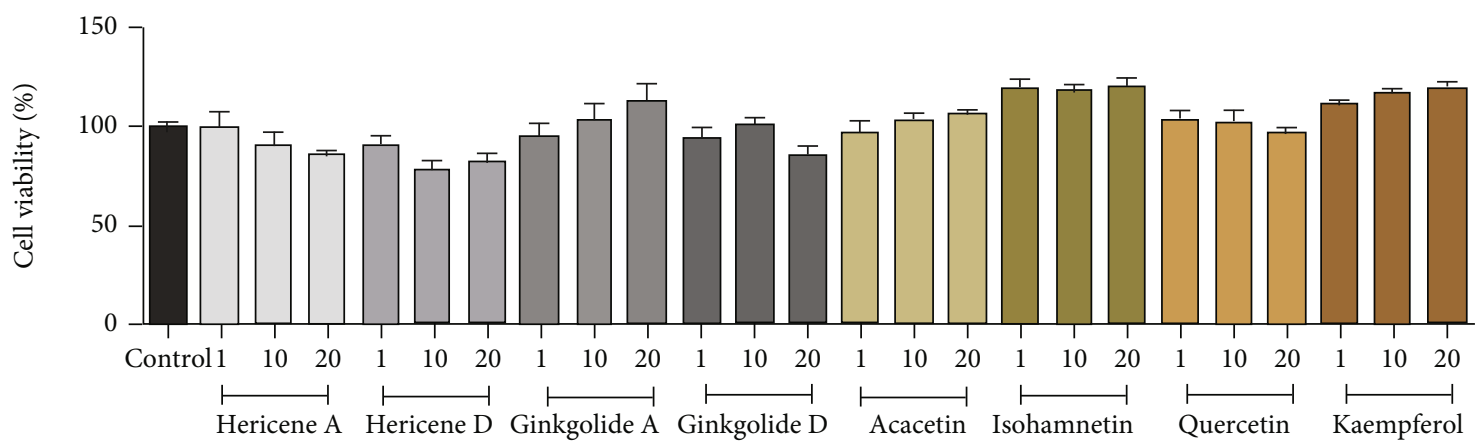

Concentration $(\mu \mathrm{M})$

(a)

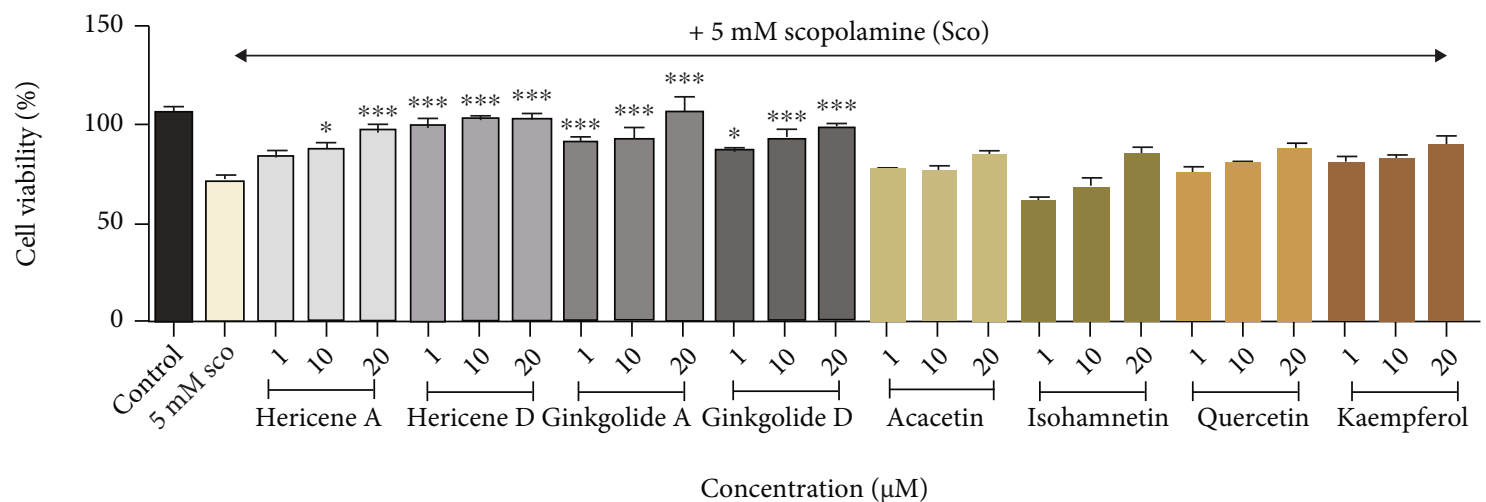

(b)

FIgURE 9: Effect of several components from the mixture (GH) of Ginkgo biloba L. leaf (GL) and Hericium erinaceus (Bull.) Pers. (HE) fruit extracts on scopolamine- (Sco-) induced SH-SY5Y neuroblastoma cells. (a) Cells were treated with hericene A, hericene D, ginkgolide A, ginkgolide $\mathrm{B}$, isorhamnetin, acacetin, quercetin, and kaempferol at 1,10 , and $20 \mu \mathrm{M}$ concentrations. Cell viability was measured by MTT assay. (b) Cells were pretreated with 1,10 , and $20 \mu \mathrm{M}$ hericene $\mathrm{A}$, hericene $\mathrm{D}$, ginkgolide A, ginkgolide B, isorhamnetin, acacetin, quercetin, and kaempferol for $1 \mathrm{~h}$ and then cotreated with $5 \mathrm{mM}$ Sco cotreated for $24 \mathrm{~h}$. Cell viability was measured by MTT assay. Data represent the mean $\pm \operatorname{SEM}(n=3)$. ${ }^{\# \#} P<0.001$ vs. control group. ${ }^{*} P<0.05,{ }^{* *} P<0.01$, and ${ }^{* * *} P<0.001$ vs. Sco-treated group.

$\mathrm{GH}$ group, the number of immunoreactive neurons in the DG region was also improved in the scopolamine-induced mouse model, suggesting that $\mathrm{GH}$ engages in immature neuron differentiation in the hippocampus (Figure 7S).

Previous studies revealed that anti-AChE agents enhance the levels of ACh in the synaptic cleft and restore memory deficits [37]. Therefore, we also evaluated the effect of GH on the levels of ACh and AChE in a scopolamine-induced mouse model. Scopolamine increased AChE activity $(0.61 \pm 0.09$ units $/ \mathrm{mg}$ protein) and reduced ACh levels $(12.15 \pm 3.32 \mathrm{nmol} / \mathrm{mg}$ protein). Meanwhile, the administration of GH significantly reversed each level (AChE activity, $0.26 \pm 0.03$ units/mg protein; ACh level, $29.96 \pm 8.62 \mathrm{nmol} /$ mg protein) in the mouse brain (Figure 5). GH might be an efficient potential therapeutic source for preventing cholinergic dysfunction associated with $\mathrm{AD}$. Also, we found that $\mathrm{HE}$ can strongly increase the content of $\mathrm{ACh}$, while the activity of AChE became lower than that by GL treatment. This finding was in agreement with a few previous studies, which demonstrated that the AChE inhibitory activity of $\mathrm{HE}$ extracts involving hericenone and hericene components showed a mild effect $[39,40]$.
The major constituents of $\mathrm{GH}$ were identified as ginkgolide A (12.632 $\pm 0.605 \mathrm{mg} / \mathrm{g})$, ginkgolide B (4.846 \pm 0.538 $\mathrm{mg} / \mathrm{g})$, quercetin $(7.693 \pm 0.741 \mathrm{mg} / \mathrm{g})$, and hericene A $(1.669 \pm 0.030 \mathrm{mg} / \mathrm{g})$ by the HPLC system (Table 1 and Figures 3S-5S). Indeed, these compounds significantly prevented cytotoxicity on scopolamine-induced SH-SY5Y cells (Figure 9). Terpene trilactone such as ginkgolide A and ginkgolide $\mathrm{B}$ purified from $\mathrm{GH}$ has anti-plateletactivating factor, antiapoptotic, antioxidative, neurotrophic, and neuroimmunomodulatory effects [42]. In our previous study, hericene $\mathrm{A}$ as a $\mathrm{HE}$ metabolite reported that it increased the expression of nerve growth factor (NGF), BDNF, and synaptophysin, which promote neuronal survival and neurite outgrowth [43]. Hericene D isolated from $\mathrm{HE}$ also showed the potent neuroprotective effect against endoplasmic reticulum (ER) stress-dependent cell death. In addition, kaempferol, quercetin, isorhamnetin, and acacetin from GL, as flavone compounds, revealed that these compounds prevented effects of brain injury and neuroinflammation and provided neuronal protection [44, 45]. Therefore, these compounds may be the active components of $\mathrm{GH}$ involved in neuroprotection in vitro 
and in vivo. The underlying mechanism of the combined effects of those for neuronal protection and synaptic plasticity in the scopolamine-induced model requires further investigation.

\section{Conclusions}

In conclusion, our results showed that mixture of $G$. biloba L. leaf (GL) and $H$. erinaceus (Bull.) Pers. (HE) fruit extracts protected neuronal cells against scopolamine-induced neuronal dysfunction. Furthermore, GH ameliorated scopolamine-induced memory impairments as observed through Y-maze and NORT behavior tests. Moreover, GH prevented cognitive impairment via BDNF/ERK/CREB pathways in a scopolamine-induced mouse model. In addition, this mixture suppressed AChE activity in the mouse brain. All evidence suggests that GH could be a useful functional nutrient for preventing cognitive impairment. Additionally, further research should be carried out on the synergic effects of $\mathrm{GH}$ mixture on neuronal protection in a dose-dependent manner.

$\begin{array}{ll}\text { Abbreviations } \\ \text { ACh: } & \text { Acetylcholine } \\ \text { AChE: } & \text { Acetylcholinesterase } \\ \text { AD: } & \text { Alzheimer's disease } \\ \text { AKT: } & \text { Protein kinase B } \\ \text { BDNF: } & \text { Brain-derived neurotrophic factor } \\ \text { CA1: } & \text { Cornu ammonis 1 } \\ \text { CA2/3: } & \text { Cornu ammonis 2/3 } \\ \text { CNS: } & \text { Central nervous system } \\ \text { CREB: } & \text { cAMP response element-binding protein } \\ \text { DCFH-DA: } & \text { 2', }{ }^{\prime} \text {-Dichlorofluorescein diacetate } \\ \text { DCX: } & \text { Doublecortin } \\ \text { DG: } & \text { Dentate gyrus } \\ \text { DMSO: } & \text { Dimethyl sulfoxide } \\ \text { ERK: } & \text { Extracellular signal-regulated kinase } \\ \text { GAPDH: } & \text { Glyceraldehyde 3-phosphate dehydrogenase } \\ \text { GH mixture: } & \text { A mixture of GL and HE extract } \\ \text { GL: } & \text { Ginkgo biloba L. leaf extract } \\ \text { GSK3 } \beta: & \text { Glycogen synthase kinase 3 beta } \\ \text { HE: } & \text { Hericium erinaceus (Bull.) Pers. } \\ \text { MTT: } & \text { 3-(4,5-Dimethylthiazol-2-yl)-2,5-diphenyl- } \\ & \text { tetrazolium bromide } \\ \text { NGF: } & \text { Nerve growth factor } \\ \text { NORT: } & \text { Novel object recognition task } \\ \text { ROS: } & \text { Reactive oxygen species. }\end{array}$

\section{Data Availability}

The data used to support the findings of this study are included within the supplementary information files.

\section{Conflicts of Interest}

The authors declare no conflict of interest.

\section{Authors' Contributions}

Conceptualization was performed by Jae Kang Lee, Seong Min Hong, and Sun Yeou Kim; validation and formal analysis were performed by Da Hye Yoon, Mi Kyeong Lee, and Seong Min Hong; data curation was performed by Da Hye Yoon and Seong Min Hong; writing (original draft preparation) was performed by Seong Min Hong; writing (review and editing) was performed by Seong Min Hong and Sun Yeou Kim; visualization was performed by Seong Min Hong; supervision was performed by Sun Yeou Kim; project administration was performed by Seong Min Hong; funding acquisition was performed by Jae Kang Lee. All authors have read and agreed to the published version of the manuscript.

\section{Acknowledgments}

We are thankful to Jae Kang Lee, CNG Bio Co., for his valuable support. This study was supported by the Korea Institute of Planning and Evaluation for Technology in Food, Agriculture, and Forestry (IPET) through the High ValueAdded Food Technology Development Program funded by the Ministry of Agriculture, Food and Rural Affairs (grant number 318027-04-2-HD030). Also, this research was funded by CNG Bio Co (Cheongju, Korea), grant number 202004580001.

\section{Supplementary Materials}

Figure 1S: body weight transition after each sample administration for 10 days. Each group was orally administered $\mathrm{GH}$ (240 mg/kg, mixture (GH) of Ginkgo biloba L. leaf (GL) and Hericium erinaceus (Bull.) Pers. (HE) fruit extracts), GL (40 mg/kg, Ginkgo biloba L. leaf), HE (200 mg/kg, Hericium erinaceus (Bull.) Pers fruit), PC (1 mg/kg, donepezil), or water. After $30 \mathrm{~min}$, Sco induced by intraperitoneal injection for making the memory deficit model. Data represent the mean $\pm \operatorname{SEM}(n=10)$. Figure 2S: effect of Ginkgo biloba $L$. leaf (GL) and Hericium erinaceus (Bull.) Pers. (HE) fruit extracts on scopolamine- (Sco-) induced cytotoxicity in SH-SY5Y neuroblastoma cells. (A, B) Cells were treated with GL or $\mathrm{HE}$ at $10,25,50,100$, and $250 \mu \mathrm{g} / \mathrm{mL}$ concentrations. Cell viability was measured by the MTT assay. (C, D) Cells were treated with GL or HE at 10, 25, 50, 100, and $250 \mu \mathrm{g} /$ $\mathrm{mL}$ for $1 \mathrm{~h}$, and then, $5 \mathrm{mM}$ Sco was cotreated for $24 \mathrm{~h}$. Cell viability was measured by the MTT assay. Data represent the mean $\pm \operatorname{SEM}(n=3)$. ${ }^{\# \# \#} P<0.001$ vs. control group. ${ }^{*} P<$ 0.05 and $^{* *} P<0.01$ vs. Sco-treated group. Figure $3 \mathrm{~S}$ : chromatograms of standard compounds (quercetin, kaempferol, isorhamnetin, and acacetin, A) and GH mixture extract (B). Amounts of each compound were analyzed using HPLC with $0.1 \%$ trifluoroacetic acid (solvent $\mathrm{A}$ ) and methanol/ $0.1 \%$ trifluoroacetic acid (solvent B) gradient system at UV $280 \mathrm{~nm}$. Figure 4S: chromatograms of standard compounds (hericene A and hericene D) and GH mixture extract (B). Amounts of each compound were analyzed using HPLC with $0.1 \%$ trifluoroacetic acid (solvent A) and methanol/ $0.1 \%$ trifluoroacetic acid (solvent B) isocratic system at UV $294 \mathrm{~nm}$. Figure 5S: chromatograms of standard compounds (ginkgolide $\mathrm{A}$ and ginkgolide $\mathrm{D}$ ) and $\mathrm{GH}$ mixture extract 
(B). Amounts of each compound were analyzed using HPLC with $72.5 \%$ water $/ 17.5 \%$ water $/ 10 \%$ isopropanol isocratic system at UV $340 \mathrm{~nm}$. Figure 6S: effect of the mixture (GH) of Ginkgo biloba L. leaf (GL) and Hericium erinaceus (Bull.) Pers. (HE) fruit extracts on scopolamine- (Sco-) induced ROS production. ROS production was measured using the DCF-DA staining assay. Cells were treated with $\mathrm{GH}$ (dissolved in PBS) at 50, 100, and $250 \mu \mathrm{g} / \mathrm{mL}$ for $1 \mathrm{~h}$, and then, $5 \mathrm{mM}$ Sco was cotreated for $1 \mathrm{~h}$. Green fluorescence (ROS generation) from $2^{\prime}, 7^{\prime}$-DCF-DA was examined by the JuLI live-cell imaging system. Scale bar indicates $500 \mu \mathrm{m}$. Figure 7S: effect of the mixture (GH) of Ginkgo biloba L. leaf (GL) and Hericium erinaceus (Bull.) Pers. (HE) fruit extracts on doublecortin (DCX) immunostaining assay. The morphological changes of dentate gyrus (DG) region from hippocampus. (Supplementary Materials)

\section{References}

[1] J. A. Soria Lopez, H. M. Gonzalez, and G. C. Leger, "Alzheimer's disease," Handbook of Clinical Neurology, vol. 167, pp. 231-255, 2019.

[2] N. Husna Ibrahim, M. F. Yahaya, W. Mohamed, S. L. Teoh, C. K. Hui, and J. Kumar, "Pharmacotherapy of Alzheimer's disease: seeking clarity in a time of uncertainty," Frontiers in Pharmacology, vol. 11, p. 261, 2020.

[3] J. Haam and J. L. Yakel, "Cholinergic modulation of the hippocampal region and memory function," Journal of Neurochemistry, vol. 142, Supplement 2, pp. 111-121, 2017.

[4] T. H. Ferreira-Vieira, I. M. Guimaraes, F. R. Silva, and F. M. Ribeiro, "Alzheimer's disease: targeting the cholinergic system," Current neuropharmacology, vol. 14, no. 1, pp. 101115, 2016.

[5] D. Cutuli, E. Landolfo, D. Decandia et al., "Neuroprotective role of dietary supplementation with omega-3 fatty acids in the presence of basal forebrain cholinergic neurons degeneration in aged mice," International Journal of Molecular Sciences, vol. 21, no. 5, p. 1741, 2020.

[6] Z. Arvanitakis, R. C. Shah, and D. A. Bennett, "Diagnosis and management of dementia: review," JAMA, vol. 322, no. 16, pp. 1589-1599, 2019.

[7] N. Mimica and P. Presecki, "Side effects of approved antidementives," Psychiatria Danubina, vol. 21, no. 1, pp. 108-113, 2009.

[8] K. S. Tang, "The cellular and molecular processes associated with scopolamine-induced memory deficit: a model of Alzheimer's biomarkers," Life Sciences, vol. 233, article 116695, 2019.

[9] W. N. Chen and K. Y. Yeong, "Scopolamine, a toxin-induced experimental model, used for research in Alzheimer's disease," CNS \& Neurological Disorders-Drug Targets, vol. 19, no. 2, pp. 85-93, 2020.

[10] M. Riad and C. C. Hithe, Scopolamine, StatPearls, Treasure Island (FL), 2020.

[11] Y. S. Oh and H. S. Jun, "Effects of glucagon-like peptide-1 on oxidative stress and Nrf2 signaling," International Journal of Molecular Sciences, vol. 19, no. 1, p. 26, 2018.

[12] C. Lu, Y. Wang, T. Xu et al., "Genistein ameliorates scopolamine-induced amnesia in mice through the regulation of the cholinergic neurotransmission, antioxidant system and the ERK/CREB/BDNF signaling," Frontiers in Pharmacology, vol. 9, p. 1153, 2018.
[13] Y. Liao, H. J. Bae, J. H. Park et al., “Aster glehniExtract ameliorates scopolamine-induced cognitive impairment in mice," Journal of Medicinal Food, vol. 22, no. 7, pp. 685-695, 2019.

[14] J. Lv, C. Lu, N. Jiang et al., "Protective effect of ginsenoside Rh2 on scopolamine-induced memory deficits through regulation of cholinergic transmission, oxidative stress and the ERKCREB-BDNF signaling pathway," Phytotherapy Research, vol. 35, no. 1, pp. 337-345, 2021.

[15] N. A. Suliman, C. N. Mat Taib, M. A. Mohd Moklas, M. I. Adenan, M. T. Hidayat Baharuldin, and R. Basir, "Establishing natural nootropics: recent molecular enhancement influenced by natural nootropic," Evidence-based Complementary and Alternative Medicine, vol. 2016, Article ID 4391375, 12 pages, 2016.

[16] S. Aguiar and T. Borowski, "Neuropharmacological review of the nootropic herb Bacopa monnieri," Rejuvenation research, vol. 16, no. 4, pp. 313-326, 2013.

[17] Q. Yuan, C. W. Wang, J. Shi, and Z. X. Lin, "Effects of Ginkgo biloba on dementia: An overview of systematic reviews," Journal of Ethnopharmacology, vol. 195, pp. 1-9, 2017.

[18] W. Froestl, A. Muhs, and A. Pfeifer, "Cognitive enhancers (nootropics). Part 1: drugs interacting with receptors," Journal of Alzheimer's disease, vol. 32, no. 4, pp. 793-887, 2014.

[19] P. S. Chong, S. Khairuddin, A. C. Tse et al., "Hericium erinaceus potentially rescues behavioural motor deficits through ERK-CREB-PSD95 neuroprotective mechanisms in rat model of 3-acetylpyridine-induced cerebellar ataxia," Scientific reports, vol. 10, no. 1, article 14945, 2020.

[20] S. R. Lee, K. Jung, H. J. Noh et al., “A new cerebroside from the fruiting bodies of Hericium erinaceus and its applicability to cancer treatment," Bioorganic \& medicinal chemistry letters, vol. 25, no. 24, pp. 5712-5715, 2015.

[21] S. Bonassi, G. Prinzi, P. Lamonaca et al., "Clinical and genomic safety of treatment with Ginkgo biloba L. leaf extract (IDN 5933 /Ginkgoselect ${ }^{\circledR}$ Plus) in elderly: a randomised placebocontrolled clinical trial [GiBiEx]," BMC complementary and alternative medicin, vol. 18, no. 1, p. 22, 2018.

[22] H. Liu, M. Ye, and H. Guo, "An updated review of randomized clinical trials testing the improvement of cognitive function of Ginkgo biloba extract in healthy people and Alzheimer's patients," Frontiers in Pharmacology, vol. 10, p. 1688, 2020.

[23] M. A. Rahman, N. Abdullah, and N. Aminudin, "Inhibitory Effect on In Vitro LDL Oxidation and HMG Co-A Reductase Activity of the Liquid-Liquid Partitioned Fractions of Hericium erinaceus (Bull.) Persoon (Lion's Mane Mushroom)," BioMed Research International, vol. 2014, Article ID 828149, 9 pages, 2014.

[24] J. H. Cheng, C. L. Tsai, Y. Y. Lien, M. S. Lee, and S. C. Sheu, "High molecular weight of polysaccharides from Hericium erinaceus against amyloid beta-induced neurotoxicity," BMC Complementary and Alternative Medicine, vol. 16, no. 1, p. 170, 2016.

[25] S. Ryu, H. G. Kim, J. Y. Kim, S. Y. Kim, and K. O. Cho, "Hericium erinaceus extract reduces anxiety and depressive behaviors by promoting hippocampal neurogenesis in the adult mouse brain," Journal of Medicinal Food, vol. 21, no. 2, pp. 174-180, 2018.

[26] G. Haghi and A. Hatami, "Simultaneous quantification of flavonoids and phenolic acids in plant materials by a newly developed isocratic high-performance liquid chromatography approach," Journal of agricultural and food chemistry, vol. 58, no. 20 , pp. $10812-10816,2010$. 
[27] B. J. Ma, H. Y. Yu, J. W. Shen et al., "Cytotoxic aromatic compounds from Hericium erinaceum," The journal of Antibiotics, vol. 63, no. 12, pp. 713-715, 2010.

[28] M. K. Mesbah, S. I. Khalifa, A. El-Gindy, and K. A. Tawfik, "HPLC determination of certain flavonoids and terpene lactones in selected Ginkgo biloba L. phytopharmaceuticals," Farmaco, vol. 60, no. 6-7, pp. 583-590, 2005.

[29] R. Venkatesan, L. Subedi, E. J. Yeo, and S. Y. Kim, "Lactucopicrin ameliorates oxidative stress mediated by scopolamineinduced neurotoxicity through activation of the NRF2 pathway," Neurochemistry international, vol. 99, pp. 133-146, 2016.

[30] J. H. Kim, S. Lee, and E. J. Cho, “Acer okamotoanum protects SH-SY5Y neuronal cells against hydrogen peroxide-induced oxidative stress," Food Science and Biotechnology, vol. 28, no. 1, pp. 191-200, 2019.

[31] P. Chanthammachat and P. Dharmasaroja, "Metformin restores the mitochondrial membrane potentials in association with a reduction in TIMM23 and NDUFS3 in MPP+-induced neurotoxicity in SH-SY5Y cells," EXCLI journal, vol. 18, pp. 812-823, 2019.

[32] L. Subedi, K. Cho, Y. U. Park, H. J. Choi, and S. Y. Kim, "Sulforaphane-enriched broccoli sprouts pretreated by pulsed electric fields reduces neuroinflammation and ameliorates scopolamine-induced amnesia in mouse brain through its antioxidant ability via Nrf2-HO-1 activation," Oxidative Medicine and Cellular Longevity, vol. 2019, Article ID 3549274, 19 pages, 2019.

[33] M. Zhang, M. Xie, D. Wei et al., "Hydroxy- $\alpha$-sanshool isolated fromZanthoxylum bungeanumattenuates learning and memory impairments in scopolamine-treated mice," Food \& Function, vol. 10, no. 11, pp. 7315-7324, 2019.

[34] M. E. Sorial and N. S. E. D. el Sayed, "Protective effect of valproic acid in streptozotocin-induced sporadic Alzheimer's disease mouse model: possible involvement of the cholinergic system," Naunyn-Schmiedeberg's archives of pharmacology, vol. 390, no. 6, pp. 581-593, 2017.

[35] A. Das, G. Shanker, C. Nath, R. Pal, S. Singh, and H. Singh, “A comparative study in rodents of standardized extracts of Bacopa monniera and Ginkgo biloba: Anticholinesterase and cognitive enhancing activities," Pharmacology Biochemistry and Behavior, vol. 73, no. 4, pp. 893-900, 2002.

[36] M. Jahanshahi, E. Nikmahzar, N. Yadollahi, and K. Ramazani, "Protective effects of Ginkgo biloba extract (EGB 761) on astrocytes of rat hippocampus after exposure with scopolamine," Anatomy \& Cell Biology, vol. 45, no. 2, pp. 92-96, 2012.

[37] C. Eyileten, L. Sharif, Z. Wicik et al., "The relation of the brainderived neurotrophic factor with microRNAs in neurodegenerative diseases and ischemic stroke," Molecular Neurobiology, vol. 58, no. 1, pp. 329-347, 2021.

[38] S. N. Rai, H. Dilnashin, H. Birla et al., "The role of PI3K/Akt and ERK in neurodegenerative disorders," Neurotoxicity research, vol. 35, no. 3, pp. 775-795, 2019.

[39] W. Wilms, M. Woźniak-Karczewska, P. F. Corvini, and L. Chrzanowski, "Nootropic drugs: methylphenidate, modafinil and piracetam - population use trends, occurrence in the environment, ecotoxicity and removal methods - a review," Chemosphere, vol. 233, pp. 771-785, 2019.

[40] N. Kuzumaki, D. Ikegami, R. Tamura et al., "Hippocampal epigenetic modification at the doublecortin gene is involved in the impairment of neurogenesis with aging," Synapse, vol. 64, no. 8, pp. 611-616, 2010.

[41] W. Chen, X. Cheng, J. Chen et al., "Lycium barbarum polysaccharides prevent memory and neurogenesis impairments in scopolamine-treated rats," Plos One, vol. 9, no. 2, article e88076, 2014.

[42] C. Li, K. Liu, S. Liu, Q. Aerqin, and X. Wu, "Role of ginkgolides in the inflammatory immune response of neurological diseases: a review of current literatures," Frontiers in systems neuroscience, vol. 14, p. 45, 2020.

[43] S. H. Ryu, S. M. Hong, Z. Khan et al., "Neurotrophic isoindolinones from the fruiting bodies of Hericium erinaceus," Bioorganic \& Medicinal Chemistry Letters, vol. 31, article 127714, 2021.

[44] B. Ahlemeyer and J. Krieglstein, "Neuroprotective effects of Ginkgo biloba extract," Cellular and Molecular Life Sciences CMLS, vol. 60, no. 9, pp. 1779-1792, 2003.

[45] H. G. Kim, M. S. Ju, S. K. Ha et al., "Acacetin protects dopaminergic cells against 1-methyl-4-phenyl-1,2,3,6-tetrahydropyridine-induced neuroinflammation in vitro and in vivo," Biological and Pharmaceutical Bulletin, vol. 35, no. 8, pp. 1287-1294, 2012. 